\title{
Animal contact as a source of human non-typhoidal salmonellosis
}

\author{
Karin Hoelzer", Andrea Isabel Moreno Switt and Martin Wiedmann
}

\begin{abstract}
Non-typhoidal Salmonella represents an important human and animal pathogen world-wide. Most human salmonellosis cases are foodborne, but each year infections are also acquired through direct or indirect animal contact in homes, veterinary clinics, zoological gardens, farm environments or other public, professional or private settings. Clinically affected animals may exhibit a higher prevalence of shedding than apparently healthy animals, but both can shed Salmonella over long periods of time. In addition, environmental contamination and indirect transmission through contaminated food and water may complicate control efforts. The public health risk varies by animal species, age group, husbandry practice and health status, and certain human subpopulations are at a heightened risk of infection due to biological or behavioral risk factors. Some serotypes such as Salmonella Dublin are adapted to individual host species, while others, for instance Salmonella Typhimurium, readily infect a broad range of host species, but the potential implications for human health are currently unclear. Basic hygiene practices and the implementation of scientifically based management strategies can efficiently mitigate the risks associated with animal contacts. However, the general public is frequently unaware of the specific disease risks involved, and high-risk behaviors are common. Here we describe the epidemiology and serotype distribution of Salmonella in a variety of host species. In addition, we review our current understanding of the public health risks associated with different types of contacts between humans and animals in public, professional or private settings, and, where appropriate, discuss potential risk mitigation strategies.
\end{abstract}

\section{Table of contents}

1. Public Health and Economic Costs Associated with Salmonella

2. Salmonella Epidemiology and Transmission Dynamics

3. Mammals as Source of Human Infection

3.1. Mammalian livestock species and Salmonella 3.1.1. The global distribution and economic importance of livestock.

3.1.2. Cattle and Salmonella

3.1.2.1. The clinical and economic importance of Salmonella infections among cattle 3.1.2.2. The public health importance of Salmonella infection among cattle

3.1.3. Small ruminants and Salmonella

\footnotetext{
* Correspondence: kh294@cornell.edu
}

Department of Food Science, 410 Stocking Hall, Cornell University, Ithaca, NY 14853, USA
3.1.3.1. The clinical and economic importance of Salmonella infections among small ruminants

3.1.3.2. The public health importance of Salmonella infection among small ruminants

3.1.4. Salmonella and pigs

3.1.4.1. The clinical and economic importance of Salmonella infections among pigs

3.1.4.2. The public health importance of Salmonella infection among pigs

3.2. Companion animals and Salmonella

3.2.1. The changing role of companion animals in the 20th century

3.2.2. Salmonella infections in horses and humans

3.2.2.1. The clinical and economic importance of Salmonella infections among horses 3.2.2.2. The public health importance of Salmonella infection among horses

3.2.3. Salmonella infections in dogs, cats and humans 
3.2.3.1. The veterinary importance of Salmonella infections among dogs and cats

3.2.3.2. The public health risk associated with

Salmonella infection among dogs and cats

3.2.4. Commercial pet food and treats as sources of infection.

3.3. Rodents, Rabbits and Salmonella

3.3.1. The clinical and environmental importance of Salmonella infections among rodents and rabbits

3.3.2. The public health importance of Salmonella infections among rodents and rabbits

3.4. The role of non-traditional mammalian pets and wildlife

3.4.1. Exotic pets, wildlife and Salmonella

4. Avian Sources of Human Salmonellosis

4.1. Overview of Salmonella infections in birds

4.2. Salmonella infections among galliform birds

4.3. Salmonella infections among anseriform birds

4.4. Salmonella infections among columbiform birds

4.5. Salmonella infections among passerine birds, psittacine birds, and other non-domesticated birds

5. Reptiles, Amphibians and Fish as Sources of Human Infection

\subsection{Reptiles and Salmonella}

5.1.1. Salmonella prevalence and serotype diversity among reptiles

5.1.2. The risk associated with contacts to reptiles

5.1.3. Salmonella - related regulations of pet turtle commerce

5.2. Amphibians and Salmonella

5.3. Fish and Salmonella

5.3.1. The risk associated with contacts to fish

6. Invertebrates and Salmonella

7. Animal Contact in Public Settings as Source of Human Infection

7.1. Human outbreaks linked to animal contacts in public settings

7.2. Current legislation and recommendations: case study USA

\section{Conclusions}

\section{Public Health and Economic Costs Associated with Salmonella}

Salmonella is an important foodborne pathogen worldwide. A recent study estimated that approx. 93.8 (95\%
Confidence Interval: 61.8-163.6) million human cases of gastroenteritis and 155000 (95\% Confidence Interval: 39000 - 303 000) deaths occur due to Salmonella infection around the world each year [1]. In the USA alone, Salmonella causes an estimated 1.4 million human cases, 15000 hospitalizations and more than 400 deaths annually $[2,3]$. However, only a fraction of cases is reported, and in the USA, only an estimated $1-5 \%$ of cases are laboratory confirmed and reported to the Centers for Disease Control and Prevention (CDC) [4]. In 2006, the national case rate in the USA equaled 13.6 reported cases per 100000 population per year [4]. Rates varied considerably by geographic region, with estimates particularly high in the Mid-Atlantic and New England States. This heterogeneity is likely in part due to differences in reporting. Differences in salmonellosis case rates between geographically and socio-economically similar USA states have been documented, with rates differing by as much as $200 \%$ between neighboring states [4]. Similarly, of the 168929 human cases reported in the European Union (EU) during 2005, 31\% stemmed from Germany even though less than $20 \%$ of the EU's population resides in Germany, again suggesting reporting differences $[5,6]$.

In 1999, non-typhoidal Salmonella infections in the USA were estimated to contribute $10 \%$ of foodborne human illnesses, $26 \%$ of hospitalizations, and $31 \%$ of deaths attributable to infections by known foodborne pathogens, thereby ranking first among all bacterial foodborne pathogens in hospitalizations and deaths and second after Campylobacter in the number of illnesses [3]. In 2009, Salmonella was the most commonly reported bacteriological agent of human foodborne disease in the USA, causing approx. $44 \%$ of confirmed foodborne bacterial infections [7]. More than 20\% of human clinical Salmonella isolates in the USA are obtained from children under the age of 5 years, emphasizing the great importance of this age group $[8,9]$. Approx. $1 \%$ of Salmonella cases are thought to require hospitalization [10]. However, due to the high prevalence of Salmonella infections, the Economic Research Service of the United States Department of Agriculture (USDA) [11] estimated the annual cost inflicted on the USA economy to equal approx. 2.5 billion US dollar, thereby clearly exceeding the annual economic cost attributable to human infections by Escherichia coli (\$460 million) or Listeria monocytogenes (\$2 billion) [12].

\section{Salmonella Epidemiology and Transmission Dynamics}

Salmonella serotypes can be divided into host restricted, host specific, and generalists serotypes, with important implications for epidemiology and public health [13]. 
Host specific serotypes, for instance serotypes Paratyphi A, Gallinarum biovars Gallinarum and Pullorum, or Typhi only cause disease in one host species [13,14]. In contrast, host restricted serotypes are predominantly associated with one host species, but can cause disease in other species as well [13]. Salmonella Dublin, for example, is adapted to cattle but infections in small ruminants, pigs and humans have also been documented, and serotype Choleraesuis is adapted to swine but has also been isolated from a range of other host species $[15,16]$. Generalist serotypes such as Salmonella Typhimurium commonly cause disease in a broad range of hosts, even though a narrow host range has been described for certain subtypes, for instance Typhimurium subtypes DT2 and DT99, which appear to be adapted to pigeons [17]. Serotypes with broad and narrow host range seem to differ in clinical manifestation even though other factors such as host species, age, and concomitant disease affect the clinical manifestation as well (see [17] for a comprehensive review). Infections with generalist serotypes are often characterized by high morbidity but low mortality, and gastro-intestinal symptoms are the predominant clinical manifestation $[13,17]$. On the contrary, infections with host adapted or restricted serotypes, such as Choleraesuis, Abortusequi, Gallinarum biovar Gallinarum, or Gallinarum biovar Pullorum, are typically characterized by low morbidity and high mortality, and systemic disease is common $[13,17]$.

Salmonella serotypes clearly seem to differ in their pathogenic potential for humans and serotype distributions often vary vastly between human and animal populations as well as among different animal populations in the same geographic area (see Additional file 1: Table S1). For instance, approximately $40 \%$ of all known Salmonella serotypes are predominantly associated with reptiles or amphibians, yet less than $1 \%$ of human salmonellosis cases are caused by these reptile-associated serotypes. The molecular determinants of serotypespecific host range differences have so far largely remained elusive. However, serotype-specific differences in virulence have been characterized in some cases. For instance, in competition experiments with Salmonella Typhimurium, reptile-associated Salmonella Arizonae and Diarizonae showed a significantly reduced ability to colonize and persist in the intestine of BALB/c mice, clearly suggesting virulence differences [18].

Majowicz et al. [1] recently estimated that approx. 80.3 of 93.8 million human Salmonella-related gastroenteritis cases that are estimated to occur globally each year are foodborne, thus representing approx. $86 \%$ of human salmonellosis cases. Another study based on formal elicitation of expert opinion estimated that approx. $55 \%$ (range $32-88 \%$ ) of human Salmonella cases are foodborne, 14\% (range 3-26\%) are travel-related, 13\% (range $0-29 \%$ ) are acquired through environmental sources, 9\% (range 0-19\%) occur due to direct humanto-human transmission and 9\% (range 0-19\%) are attributable to direct animal contact $[5,19]$. Yet another study, based on surveillance data, estimated that $95 \%$ of non-typhoidal human Salmonella cases in the USA are foodborne, emphasizing the complexity and controversy of the subject matter [3]. Food products derived from the animal species discussed in this review can also serve as sources of human infection, and such products have been implicated in numerous human outbreaks. However, as this review focuses on animal-acquired infection, foodborne infections will not be further discussed here. Several excellent reviews of foodborne salmonellosis have been published in recent years, and the reader is referred to these publications for further details regarding infections associated with the consumption of meat, eggs, dairy products, vegetables, reptile products, and other foods (see for instance [10,20-29]).

The comparison of Salmonella outbreak and surveillance data across geographic regions or from different time periods represents a considerable challenge. The advent of novel molecular subtyping methods has noticeably improved discriminatory power, with important impacts on sensitivity and specificity [30]. The impacts of differences in public health infrastructure, disease surveillance sampling plans, public health legislation etc. are difficult to measure, but differences in apparent prevalence between states or countries are clearly noticeable. Case and outbreak definitions are also variable. For clarity, we will henceforth define "case" to refer to any instance where strong epidemiological or molecular evidence suggests an animal source of human infection, while trying to point out instances where such conclusions are solely based on serotype data or circumstantial epidemiological links. Furthermore, we will define an outbreak as an event where two or more human cases are presumably linked to the same source. We acknowledge that the epidemiological definition of an outbreak differs from this definition, but due to the large amount of underreporting and the problem of attributing cases with broad host-range serotypes to animal sources we chose this definition.

As some serotypes are strongly associated with specific animal species and some case definitions utilize serotype data to define for instance reptile-acquired cases (see for instance [31,32]), serotype-dependent differences in case detection are likely. Similarly, unusual exposures, such as those attributable to newly acquired or exotic pets, visits to animal exhibits, or contacts with clinically sick animals, are more likely to be recalled than routine exposures (see for instance [33-36]). In addition, small outbreaks are probably less likely to be reported in the peer-reviewed 
literature. Animal acquired infections are therefore probably strongly underreported, and the data is potentially biased towards larger outbreaks, uncommon serotypes, certain animal species, and unusual exposures.

\section{Mammals as Source of Human Infection}

3.1. Mammalian livestock species and Salmonella

3.1.1. The global distribution and economic importance of mammalian livestock

The estimated number of mammals farmed for agricultural purposes around the world exceeds 4 billion animals [37]. In 2006, approx. $20 \%$ of the world's population, equaling approx. 1.3 of 6.55 billion people, were employed in the livestock sector, and livestock accounted for approx. $40 \%$ of global agricultural output [38]. An estimated 1 billion pigs and 2 billion small ruminants are farmed worldwide [39]. The global cattle population is believed to equal approx. 1.3 billion animals, and 181 million buffaloes as well as approx. 24.7 million camels are farmed for commercial purposes around the world [37]. The relative and absolute abundance of livestock differs considerably by country and geographic area. For instance, the USA is the world's largest producer of beef and the third-largest producer of pork, while large numbers of cattle and pigs are also farmed in the EU [37]. Australia is a leading producer of wool and sheep meat, and India is an important producer of goat, buffalo and cow milk and a leading producer of goat and buffalo meat. Africa as well as parts of Western Asia are major producers of camel and goat products [37].

\subsubsection{Cattle and Salmonella}

3.1.2.1. The clinical and economic importance of Salmonella infections among cattle Abortions attributable to Salmonella infection are possible but rare in cattle, thus economic losses in cattle operations are primarily due to increased mortality, performance losses, and direct and indirect costs associated with treatment and infection control (see [40] for a review of the topic). Mortality rates attributable to Salmonella infection are particularly high in young animals, which also generally require the greatest amount of treatment. Significant weight losses in calves due to Salmonella infection have been reported in numerous studies, even though surviving calves seem to regain the weight after recovery (see [40]). In addition, Salmonella infection often leads to increased feed costs due to diminished feed conversion [40].

Clinically, Salmonella infection in cattle is typically manifested as watery or bloody diarrhea, and often associated with fever, depression, anorexia, dehydration and endotoxemia. Less common clinical manifestations include abortion and respiratory disease, and mortality rates can be high. Particularly in adult animals
Salmonella frequently causes subclinical disease, and is known to persist on infected farms for months or years [41-44]. Individual animals shed Salmonella intermittently, over variable periods of time, and infections with host adapted serotypes such as Salmonella Dublin may potentially result more frequently in the development of asymptomatic shedders than infections with broad hostrange serotypes [45]. One recent study estimated the median duration of shedding in dairy cattle to equal 50 days, with a maximum duration of 391 days, and the results appear comparable to previous reports $[46,47]$. However, the duration of Salmonella persistence in herds exceeds maximum shedding durations observed for individual animals, and is believed to be largely attributable to endemic Salmonella infections within the herd [47]. Several studies report isolating Salmonella at high rates from farm environments, a likely important Salmonella reservoir [43,47-50].

Salmonella within- and between-herd prevalence estimates vary considerably, with between-herd point prevalence estimates for cattle operations ranging from $2-42 \%$ and within-herd estimates for these operations ranging from $0-37 \%$ [47,51-57]. In addition, herds with clinically sick animals are generally characterized by higher within-herd prevalence than herds where clinical salmonellosis is absent, and serotype distribution may differ between herds with and without clinical cases [58-63]. Large herd size represents an important risk factor for salmonellosis, and the risk of Salmonella shedding seems to vary by production system, housing type, general hygiene level, management type and animal age, although the results reported in the literature have been somewhat contradictory [64]. Calves, heifers, and periparturient cows generally appear to be at a particular risk of infection, and one study found heifers and periparturient cows to be the most likely cattle to become asymptomatic carriers $[47,65,66]$.

The distribution of Salmonella serotypes among cattle varies greatly over time, and differs among geographic regions, age groups, clinical manifestation, and production systems. The United States National Veterinary Service Laboratory (NVSL), for instance, reported that serotypes Typhimurium, Newport, Orion, Montevideo, and Agona were the serotypes most frequently isolated from clinically sick cattle in 2005 and 2006, while serotypes Cerro, Kentucky, Anatum, Newport, Montevideo, and Orion were the serotypes most frequently isolated from clinically healthy cattle in the same time period [67]. In 2007, serotypes Cerro, Kentucky, Montevideo, Muenster, Meleagridis, Mbandaka and Newport were the serotypes most commonly isolated from healthy dairy cattle in the USA, while serotypes Montevideo, Meleagridis, Cerro, Mbandaka, Typhimurium, Anatum, Give, Kentucky, Muenchen and Senftenberg had been 
the serotypes most commonly isolated from healthy USA dairy cattle in 1996 [68]. In comparison, serotypes Montevideo, I 6,7:k:-, Braenderup, Meleagridis, Newport and I 3,10:-:1, were the serotypes most commonly isolated from USA beef cattle in 2007/2008, and serotypes Typhimurium, Anatum, Dublin, Montevideo, and Newport were the serotypes most commonly isolated from USA beef herds in 1999 [69,70]. The implications of these differing serotype distributions for human health, however, are currently difficult to assess.

3.1.2.2 The public health importance of Salmonella infection among cattle Cattle play a paramount role as source of foodborne infection, and a considerable number of serotypes frequently isolated from humans have been isolated from sick or clinically healthy cattle (Additional file 1: Table S1). Some human cases have also been linked to direct cattle exposure (Table 1). For instance, in 2002 and 2004, human Salmonella Newport outbreaks in Michigan were linked to cattle contact in a public setting; in 2001, Salmonella Newport was transmitted to humans during a farm visit, even though the consumption of contaminated raw milk may have been a contributing factor; and in 2000, serotype Typhimurium was transmitted to children at a farm camp. In several instances, attribution of human cases to cattle exposure is further complicated by simultaneous consumption of raw milk or cheese from the same farm, as illustrated by recent outbreaks of Salmonella Newport and Dublin (Table 1). Nail biting, contact with manure, thumb sucking, eating, or having soiled hands and shoes have been identified as risk factors for animal-acquired E. coli infections, and a similar role for Salmonella appears likely [71]. Much less is known about the Salmonella risk posed to humans by indirect animal contacts, especially through environmental contamination. Further studies, especially on spatial clustering of human cases around livestock premises, are needed to assess the indirect risks posed by livestock operations.

In conclusion, the studies summarized above show that direct cattle contacts represent a potential human health risk. Clinically sick animals probably pose the greatest risk to humans because they are more likely to shed Salmonella, and at higher concentration, than apparently healthy animals. However, even asymptomatic carriers can shed Salmonella for long periods of time, and increased stress, as often experienced during exhibitions, represents an important risk factor for shedding. In addition, herds with clinical signs of Salmonella have higher within-herd prevalence than those without clinical signs, Salmonella prevalence is correlated with animal age as well as management-related factors, and environmental contamination can play an important epidemiologic role. Clinically affected herds and certain management systems may therefore pose an increased risk to the public. Several additional management practices may mitigate the human health risk associated with cattle contacts, for instance strict enforcement of good hygiene practices, the prevention of contact with manure, or targeted education of vulnerable human subpopulations. Several Salmonella infections have been attributed to occupational livestock contact (see for instance $[36,72,73])$. Surprisingly, a considerable number of cutaneous infections among veterinarians have been reported as results of obstetric manipulations, reinforcing the need for good hygiene practices and adequate protective equipment (Table 1). However, quantitative estimates of the occupational risks are scarce. One study reported Salmonella-specific antibodies in $60 \%$ of poultry workers and nearly $10 \%$ of workers in meat-packaging plants in Russia, with highest prevalence among those handling sick poultry or pathological material (or consuming raw meat sausages) [74]. Similarly, occupational transmission of Salmonella Typhimurium to a slaughterhouse employee has been reported by Molbak et al. [75]. Another study found nearly $9 \%$ of poultry workers and $6 \%$ of duck workers were Salmonella carriers, with intermittent clinical symptoms [76]. Conversely, another study of Salmonella Muenster reported no occupational transmission in an affected dairy herd, but the study relied exclusively on self-reporting of clinical disease in farm personnel, and sample size as well as observational period were limited [77]. Future studies are therefore clearly needed to understand the magnitude and specific nature of the risks associated with occupational exposure.

\subsubsection{Small ruminants and Salmonella}

3.1.3.1. The clinical and economic importance of Salmonella infections among small ruminants The severity and clinical manifestation of Salmonella infection in small ruminants differs by age group and serotype [78]. Acute enteric salmonellosis is common in adult sheep, leading to fever, anorexia, depression, and diarrhea, while septicemia is common in young animals $[79,80]$. However, asymptomatic carriage, chronic gastro-enteritis, and abortion have also been described [80,81]. Late term abortion, mortality in ewes, and high calf mortality can lead to extensive economic losses in sheep operations, making Salmonella abortion one of the economically most important diseases of small ruminants [40]. Abortion due to infection with serotypes such as Typhimurium or Dublin has been reported, but abortion is most frequently caused by Salmonella Abortusovis, an ovine-adapted serotype that also occasionally infects goats, and abortion generally occurs in the last weeks before parturition [78,82-84]. Infections of ewes with serotype Abortusovis can also lead to stillbirth, metritis, placental retention, or peritonitis, and infected ewes may present with fever, anorexia, and depression prior 
Table 1 Documented reports of Salmonella transmissions from mammals to humans available in the peer-reviewed literature or otherwise published by public health agencies

\begin{tabular}{|c|c|c|c|c|c|c|}
\hline $\begin{array}{l}\text { Outbreak } \\
\text { source }\end{array}$ & Year & $\begin{array}{l}\text { Salmonella } \\
\text { serotype }\end{array}$ & Type of contact & $\begin{array}{l}\text { Human } \\
\text { cases }\end{array}$ & Country & Reference \\
\hline \multicolumn{7}{|l|}{ Livestock } \\
\hline Cattle & $2005^{a}$ & Stanley & occupational (dead calf delivery); pustular dermatitis & 1 & UK & {$[36]$} \\
\hline Cattle & 2004 & Newport & public setting & 6 & USA & {$[35]$} \\
\hline Cattle & 2003 & Newport & public setting & 3 & USA & {$[35]$} \\
\hline Cattle & 2002 & Newport & public setting & 6 & USA & {$[35]$} \\
\hline Cattle & 2001 & Newport & farm visit; potentially raw milk consumption & 4 & USA & {$[35]$} \\
\hline Cattle & 2000 & Typhimurium & farm day camp & 1 & USA & {$[35,304]$} \\
\hline Cattle & 1998 & Typhimurium & household or farm environment & 1 & USA & {$[305]$} \\
\hline Cattle & 1990 & Virchow & occupational (dead calf delivery); dermatitis & 2 & Netherlands & {$[306]$} \\
\hline Cattle & 1983 & Newport & farm environment, nocosomial, feed-borne & 1 & USA & {$[307]$} \\
\hline Cattle & 1979 & Dublin & farm environment, nocosomial, potentially raw milk & $\mathrm{n} / \mathrm{a}$ & USA & {$[307]$} \\
\hline Cattle & 1976 & Heidelberg & farm environment, secondary perinatal \&nocosomial & $\mathrm{n} / \mathrm{a}$ & USA & {$[307]$} \\
\hline Cattle & 1975 & Dublin & $\begin{array}{l}\text { occupational (dead calf delivery); pustular dermatitis; } 3 \\
\text { cases }\end{array}$ & 3 & UK & {$[308]$} \\
\hline Cattle & 1973 & Saintpaul & occupational (dead calf delivery); folliculitis & 3 & Canada & [309] \\
\hline Cattle & 1973 & Typhimurium & farm environment, animal feed pot. source & $\mathrm{n} / \mathrm{a}$ & USA & {$[307]$} \\
\hline Cattle & 1972 & Typhimurium & occupational, farm environment & $\mathrm{n} / \mathrm{a}$ & USA & {$[307]$} \\
\hline Cattle & 1969 & Dublin & occupational (dead calf delivery); pustular dermatitis & 1 & UK & [308] \\
\hline Cattle & 1965 & Typhimurium & farm environment, cow and newborn calf & 2 & Canada & [310] \\
\hline Cattle & 1948 & Typhimurium & farm environment, household, well water & 7 & Canada & {$[311]$} \\
\hline Cattle/Pigs & 2001 & Typhimurium & farm or household (contaminated clothes) & 1 & Netherlands & {$[37]$} \\
\hline Pigs & 2005 & Typhimurium & public setting; potentially environmental & 19 & USA & {$[35]$} \\
\hline Sheep & $1998-2003^{b}$ & Brandenburg & occupational, household, prob. secondary dogs & $n / a$ & $\begin{array}{l}\text { New } \\
\text { Zealand }\end{array}$ & [97] \\
\hline Sheep/Cattle & 1991-1993 & Typhimurium & occupational, household, farm environment & 9 & UK & {$[73]$} \\
\hline Sheep & 1975 & Typhimurium & $\begin{array}{l}\text { occupational, farm environment, secondary dog } \\
\text { infected }\end{array}$ & 1 & UK & {$[72]$} \\
\hline Livestock & 2000 & Typhimurium & petting zoo, animal source unclear & 18 & US & {$[303]$} \\
\hline Livestock & 1991 & Typhimurium & science fair, animal source unclear & 5 & US & {$[303]$} \\
\hline \multicolumn{7}{|l|}{ Equines } \\
\hline Horse & 2001 & Newport & state fair, horse clinically sick & 2 & USA & {$[35]$} \\
\hline Horse & 1995/1996 & Typhimurium & occupational, veterinary hospital, secondary ruminants & 2 & USA & {$[145,312]$} \\
\hline Horse & 1976 & Typhimurium & occupational, veterinary hospital, secondary dog & 1 & USA & {$[313]$} \\
\hline Horse & $1967 / 1968$ & Typhimurium & $\begin{array}{l}\text { occupational, veterinary hospital, complex } \\
\text { epidemiology }\end{array}$ & $2-14^{*}$ & UK & [314] \\
\hline Horse & 1936 & Abortusequi & occupational, gynecological exam, developed abscess & 1 & Japan & {$[315]$} \\
\hline \multicolumn{7}{|c|}{ Canines \& Felines } \\
\hline Cat & 1999 & Typhimurium & occupational, veterinary clinic & 10 & USA & {$[316]$} \\
\hline Cat & 1999 & Typhimurium & household, secondary daycare contact, shelter cats & 7 & USA & {$[316]$} \\
\hline Cat & 1999 & Typhimurium & $\begin{array}{l}\text { occupational, veterinary clinic, secondary } \\
\text { environmental }\end{array}$ & 3 & USA & {$[316]$} \\
\hline Cat/Dog & 2003 & Typhimurium & occupational, veterinary clinic, household infections & 7 & USA & {$[317]$} \\
\hline Cat/wild birds & 1999 & Typhimurium & household, prob. complex transmissions & $\mathrm{n} / \mathrm{a}$ & Sweden & {$[318]$} \\
\hline Cat/Dog & 1973 & Typhimurium & household, dog and cat breeder, common food source & 4 & Canada & [319] \\
\hline Dog & 1974 & Enteritidis & household & 1 & USA & [148] \\
\hline Dog & 1952 & Paratyphi B & household & 1 & UK & {$[320]$} \\
\hline Dog & 1938 & Glostrup & household, pot. common food source & 6 & Denmark & {$[321,322]$} \\
\hline Dog & 1937 & Paratyphi $B^{1}$ & household & 6 & Norway & {$[322,323]$} \\
\hline Dog & 1938 & Paratyphi B & household, caused abortion in bitch & 4 & Sweden & {$[322,324]$} \\
\hline
\end{tabular}


Table 1 Documented reports of Salmonella transmissions from mammals to humans available in the peer-reviewed literature or otherwise published by public health agencies (Continued)

\begin{tabular}{|c|c|c|c|c|c|c|}
\hline \multicolumn{7}{|c|}{ Pet food \& Treats } \\
\hline Dry pet food & $2006-2008$ & Schwarzengrund & household & 70 & USA & [325] \\
\hline Pet treats & $2004 / 2005$ & Thompson & household & 9 & $\begin{array}{l}\text { USA \& } \\
\text { Canada }\end{array}$ & [326] \\
\hline Pet treats & 2002 & Newport & household & 5 & Canada & [327] \\
\hline Pet treats & 1999 & Infantis & household, dogs potential shedders & 12 & Canada & [328] \\
\hline \multicolumn{7}{|l|}{ Rodents } \\
\hline Guinea pig & 2000 & Oranienburg & household, guinea pig soft-tissue abscess and died & 1 & USA & [329] \\
\hline Guinea pig & 1967 & Enteritidis & breeding colony in household & 3 & Canada & [330] \\
\hline Rodents & 2005/2006 & Typhimurium & classroom or household, snakes fed frozen rodents & $7-21^{*}$ & USA & [331] \\
\hline Rodents & $2003 / 2004$ & Typhimurium & household, sick pet rodents, secondary household & $15-28^{*}$ & USA & [332] \\
\hline \multicolumn{7}{|c|}{ Non-traditional mammalian pets/wildlife } \\
\hline Hedgehogs & 2002 & Typhimurium & household, potentially eggs & 6 & Australia & [333] \\
\hline Hedgehogs & 2000/2001 & Typhimurium & $\begin{array}{l}\text { unclear, wild animals, potentially contaminated } \\
\text { produce }\end{array}$ & 37 & Norway & [192] \\
\hline Hedgehogs & 1996 & Typhimurium & $\begin{array}{l}\text { unclear, wild animals, potentially contaminated } \\
\text { produce, } 2 \text { outbreaks }\end{array}$ & $28-65^{*}$ & Norway & [192] \\
\hline Hedgehogs & 1995-1997 & Tiliene & $\begin{array}{l}\text { household, pet hedgehogs, multiple outbreaks, } \\
\text { interspecies transmission }\end{array}$ & 9 & Canada & [334] \\
\hline Hedgehogs & $1994 / 1995^{\complement}$ & Typhimurium & household, pet hedgehog & 1 & Canada & [196] \\
\hline Hedgehogs & 1994 & Tiliene & $\begin{array}{l}\text { household, pet hedgehog, indirect contact, breeding } \\
\text { herd in household }\end{array}$ & 1 & USA & [335] \\
\hline Sugar glider & 1995 & Tiliene & household & 1 & Canada & [334] \\
\hline Wallaby & 2003 & Enteritidis & farm environment, traveling petting zoo & 17 & USA & [35] \\
\hline
\end{tabular}

${ }^{1}$ identical to serotype Abortuscanis.

a estimated time of outbreak, exact time not specified; ${ }^{b}$ estimated time period for prolonged nationwide outbreak; ' ${ }^{c}$ exact time of outbreak not specified more precisely; *exact number of cases unclear; $\mathrm{n} / \mathrm{a}$ exact number of cases not specified.

to abortion [85]. Mortality rates in ewes are highly variable, and mortality is often associated with the occurrence of secondary diseases such as placental retention. Neonatal mortality in affected herds is usually high. Lambs carried to term frequently die of septicemia [78]. While neonates often die within hours of birth, lambs can in some cases survive for weeks, and in these instances disease is often manifested as polyarthritis, pneumonia, and severe diarrhea. Salmonella Abortusovis infection in non-pregnant ewes and rams appears to be predominantly asymptomatic and venereal infection have been described in some instances [86].

The prevalence of Salmonella among small ruminants seems to vary considerably between serotypes, herds, and geographic regions. Large outbreaks of Salmonella Abortusovis among sheep have been reported repeatedly, for instance in Switzerland, where infections with serotype Abortusovis seem to have contributed up to 70\% of lambing losses between 2003 and 2007 [87]. The prevalence of serotype Abortusovis within herds can be high, and within-herd prevalence estimates of between 20 and $50 \%$ have been reported [82,87]. Animals that survive infection with Salmonella Abortusovis usually develop robust immunity, so that infections tend to be associated with primigravide animals [82]. Salmonella Diarizonae is the causative agent of winter dysentery, a disease of sheep that is also associated with abortion and stillbirth. Serotype Diarizonae represents another common, sheep-adapted serotype. The prevalence of serotype Diarizonae in Norwegian sheep herds, for instance, has been estimated at approx. $12 \%$, with within-herd prevalence in the range of $0-45 \%$, even though the samples were collected at the abattoir and increased stress may have contributed to the high observed prevalence [88]. Other studies have also reported a high prevalence of various Salmonella serotypes including for instance serotypes Typhimurium, Anatum, or Saintpaul, in goats and sheep at slaughterhouses in different countries, with prevalence estimates generally in the range of $17-60 \%$, even though a considerably lower prevalence among slaughtered goats and sheep in India and Ethiopia has been reported in some studies [81,89-93]. The prevalence of Salmonella among healthy goats and sheep on farms generally appears to be considerably lower, with reported prevalence estimates often in the range of $0-4 \%[94,95]$. However, 
environmental contamination on farms is potentially high, and Edrington et al. [96], for instance, reported isolating Salmonella from 50\% of wool samples but only $7 \%$ of fecal samples collected from feedlot sheep in the USA, indicating a potentially important epidemiological role of environmental reservoirs.

\subsubsection{The human public health importance of Salmonella infections among small ruminants}

A limited number of zoonotic transmissions from sheep to humans have been reported in the literature, mostly associated with occupational exposures (Table 1). For instance, occupational sheep exposure was found to be significantly associated with human Salmonella Brandenburg infections in New Zealand [97]. In addition, human outbreaks have repeatedly been linked to occupational contacts on farms in the UK, reiterating the potential public health importance of sheep and goat contacts [73].

In conclusion, Salmonella infections represent an economic and potential public health risk on sheep and goat farms, but considerable differences between the serotypes exist. Infections with serotype Abortusovis are responsible for large economic losses, but carry little health hazards for humans. However, several other serotypes such as Typhimurium can cause similar clinical disease in ewes, with potentially important implications for human health. Good hygiene practices and personal protective clothing are crucial to prevent occupational infections, especially during lambing or obstetrical intervention. Secondary transmissions to family members after occupational exposure have also been documented, reinforcing the importance of good hygiene practices on farms to reduce the human health risk [73]. Animals with clinical signs of gastro-intestinal disease or septicemia may pose the highest risk for humans, but asymptomatic shedding at relatively high prevalence has been documented at slaughter, indicating that clinically healthy animals may also pose a considerable risk. Salmonella carriage among healthy animals on farms appears to be relatively rare, but environmental contamination likely contributes to the infection risk. In conclusion, contacts with small ruminants pose a potential health risk to occupationally exposed subpopulations as well as the general public, but the risk depends strongly on the serotype involved.

\subsection{Salmonella and pigs}

\subsubsection{The clinical and economic importance of Salmonella} infections among pigs

A variety of clinical manifestations have been observed in Salmonella infected pigs, ranging from asymptomatic to peracute disease. Infections with generalist serotypes such as Typhimurium usually cause mild or no disease, and infected animals may shed Salmonella for considerable periods of time. For instance, piglets experimentally inoculated with Salmonella Typhimurium developed mild gastro-intestinal disease and were found to shed bacteria in their feces for several days [98]; however, systemic disease and mortality associated with broad host-range serotypes has also been reported [99]. In contrast, infection with host adapted serotype Choleraesuis generally causes severe systemic disease with high mortality (see [99] for a recent review). All age groups are susceptible to Salmonella infection, but disease is most commonly observed among weaned pigs more than eight weeks of age, and asymptomatic carriers are thought to represent the most important source of Salmonella introduction onto pig farms. A variety of clinical manifestations have been documented among Salmonella-infected pigs, including enteritis, septicemia, pneumonia, meningitis, and arthritis. Fever, diarrhea, inappetence, depression, respiratory distress, lameness, edema, and hypoxia in the extremities are common symptoms in clinically sick pigs, and mortality rates in such instances are high. Schofield [100], for instance, reported salmonellosis outbreaks among pigs manifested as ataxia, fever, depression, diarrhea, and necrotic enteritis, which resulted in approx. 17\% mortality.

Salmonella prevalence estimates for pig farms seem to differ considerably by production and management type, with average between-herd estimates in the USA equaling 53\% in 2006 and exceeding $80 \%$ for some farrow-tofinish production systems, while within-herd estimates range from 3.5 to 28\% [58-63]. High Salmonella prevalence on pig breeding farms and considerably lower prevalence on replacement gilt development farms have been described in one study [58]. However, another study reported high prevalence among replacement gilts and finishing gilts, suggesting variability between herds and studies [60]. Surprisingly, Davies et al. [101] reported a higher Salmonella prevalence in all-in-all-out than continuous flow management systems, and distinct Salmonella serotype populations in breeding herds, nursery and finishing herds from the same farrow-to-finish system have been reported [101]. Breeding herds or nurseries therefore seem to represent epidemiologically relatively unimportant sources of infection in finishing herds, and environmental contamination may play an important role in maintaining endemic infections. In fact, Dahl et al. [102] demonstrated that Salmonella free finishing herds can be produced from endemically infected herds if pigs are strategically moved to clean stalls as they move through the farrow-to-finish system. Reducing the prevalence of Salmonella is particularly important because Salmonella prevalence at slaughter tends to be considerably higher than on farm [64]. Indeed, one study reported 7-fold higher Salmonella 
prevalence in pigs sampled at the abattoir than in animals from the same herds sampled on farm, indicating an important effect of stress or other transportationrelated factors [103]. In addition to host adapted serotype Choleraesuis, serotypes Typhimurium, Derby, Agona and Anatum are frequently isolated from sick and clinically healthy pigs, indicating a potential risk for human health (Figure 1, Additional file 1: Table S1).

3.1.4.2. The human public health importance of Salmonella infections among pigs On few occasions, likely zoonotic transmissions of Salmonella from pigs to humans have been described (Table 1). For instance, in 2005, a Typhimurium outbreak among humans in Wisconsin was linked to indirect pig contact in a public setting [34]. Similarly, in 2001 occupational exposure to pigs likely led to human infection, even though in this case the possibility of a transmission from calves could not be conclusively eliminated [36].

In conclusion, Salmonella represents an occupational hazard for those working with pigs, especially since asymptomatic carriage of broad host-range serotypes appears to be relatively common. Environmental reservoirs appear to play an important role in maintaining endemic infections, and contaminated clothing has been implicated in the transmission of Salmonella from pigs or calves to the son of a farmer, indicating the paramount importance of good hygiene practices [36]. Stress probably represents a major reason for the increased Salmonella prevalence among pigs at slaughter relative to that observed on farms, and a similarly increased prevalence of shedding during exhibitions or at other public venues appears likely. Contact with pigs on farms, at the slaughterhouse, or in the scope of public exhibitions therefore likely represents a risk to occupationally exposed population subgroups and the general population.

\subsection{Companion animals and Salmonella}

\subsubsection{The changing role of companion animals in the $20^{\text {th }}$}

\section{century}

The keeping of animals as pets has a long tradition, but historically, companion animals were foremost held for labor [104,105]. Dogs served as guard dogs, hunting companions, or were used for herding, while cats were kept to catch rodents. Dogs and cats were rarely kept in homes, even pet animals [104]. During the $19^{\text {th }}$ century engine-powered machines replaced horses as sources of labor. Simultaneously, the public's attitude towards animals changed, manifested in the foundation of animal welfare organizations such as the British Royal Society for the Prevention of Cruelty to Animals (RSPCA) in $1824[104,105]$. The number of pet animals held for companionship increased drastically after World War II [104]. Currently, an estimated $63 \%$ of households in the USA own at least one pet; approximately 83.2 million households own dogs or cats, and roughly 4.3 million households own horses [106]. Similarly, in the United Kingdom, an estimated $26 \%$ of households own cats and $31 \%$ of households own dogs, amounting to approximately 10.3 million cats and 10.5 million dogs [85]. Today, dogs and cats primarily live indoors, share living

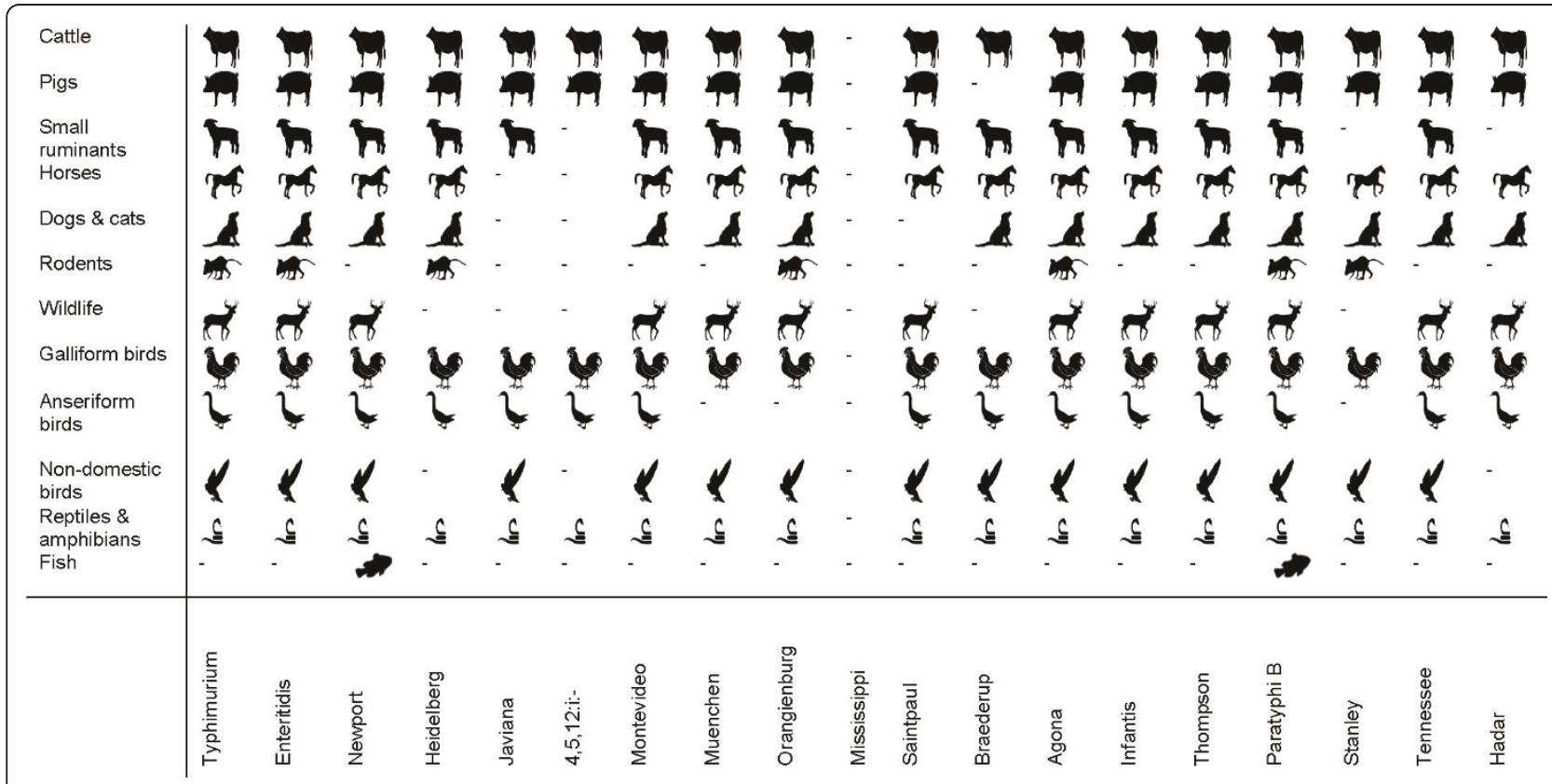

Figure 1 Distribution of the 20 most common human Salmonella serotypes [7]among animals, based on US data from 2006. Salmonella Typhi was excluded from this analysis as it represents a host-restricted serotype adapted to humans and non-human primates. 
spaces with their owners, and assume integral roles as companions, family members, or service animals $[104,107]$. In one recent survey $95 \%$ of USA dog owners reported petting their animals, $67 \%$ reported playing with them, and 30\% reported sharing their beds with their dogs [108]. Companion animals are also increasingly used in therapeutic settings, for instance in psychotherapy, or to support AIDS patients, children with disabilities, orthopedic and cardiac patients, Alzheimer patients, or the elderly [109-114]. The potential risks associated with such contacts, particularly for young children or immune-compromised patients, are difficult to quantify. In some parts of the world, companion animals still fulfill functional roles as source of food or labor, and may be allowed to roam around freely [115].

\subsubsection{Salmonella infections in horses and humans}

3.2.2.1. The clinical and economic importance of Salmonella infections among horses Salmonellosis is an important disease of horses. Equine mortality rates vary depending on host age, predisposing factors and potentially the Salmonella serotype involved [116]. Mortalities as high as 40 to $60 \%$ have been reported, but in general, mortality appears to be considerably lower $[117,118]$. In most cases, animals present with profuse, watery and malodorous diarrhea, frequently associated with abdominal pain and endotoxemia. Fever, dehydration and depression are common, and in severe cases these symptoms are accompanied by colic, gastric reflux, cardiovascular shock or coagulopathies. However, the severity of disease can vary considerably and, in animals of the same age group, may range from severe to asymptomatic [119]. Both peracute and chronic forms of disease are common, and convalescent carriers may shed Salmonella for months, but a carrier state does not appear to develop in all instances $[118,120,121]$. Disease may also manifest without gastrointestinal signs. Some serotypes appear to result more frequently in systemic disease than others, but the underlying mechanisms are still incompletely understood [122]. Respiratory forms are comparably frequent, and systemic forms of infection are commonly associated with arthritis, osteomyelitis, or softtissue abscesses [123,124]. Foals, pregnant mares, and immune compromised horses are at a heightened risk of infection and, among foals, Salmonella-associated meningoencephalitis has been described $[125,126]$. Abortions due to Salmonella cause important economic losses on stud farms [127-129].

Numerous studies have focused on horses in equine hospitals, with apparent prevalence estimates ranging from 1.8 to 18\%; Anderson and Lee, however, report isolating Salmonella from $26.6 \%$ of slaughter horses [125,130-135]. The prevalence among healthy horses on farms or in riding schools appears to be considerably lower, in the range of 1 to $2 \%[117,131,135,136]$. Asymptomatic carriers shed Salmonella intermittently. Increased shedding has been associated with antibiotic treatment and stressful situations such as transportation, horse competitions, co-morbid disease, or surgery [125,133,137-140]. High population density is thought to be another predisposing factor. The epidemiological significance of environmental contamination remains difficult to assess, but good environmental hygiene practices have been efficient in controlling hospital outbreaks [132,141-143]. Numerous serotypes have been isolated from clinically healthy or sick horses, and a considerable number of outbreaks involving a variety of medically important serotypes have occurred in large animal hospitals (Table 1, Additional file 1: Table S1).

3.2.2.2. The public health importance of Salmonella infection among horses Zoonotic transmission in large animal veterinary hospitals and private veterinary clinics is thought to occur frequently, even though only a small number of human cases associated with such transmissions have been documented (Table 1) [144,145]. Salmonella transmission to humans at a state fair has also been reported (Table 1) [34].

In conclusion, horse contacts clearly represent a risk to humans. However, clinically healthy horses in riding schools or on farms, especially if held under optimal conditions, seem to pose a comparably low risk. The risk at competitions, state fairs or other public venues might be considerably higher due to increased stress, whereas pregnant mares, foals and hospitalized horses clearly represent a high risk. Salmonella-infected horses often present with no or atypical clinical symptoms, emphasizing the need for strict quarantine, environmental contamination control, and good hygiene practices. Due to the high Salmonella prevalence, high risk population subgroups may choose to refrain from entering equine hospitals or stud farms, or take particular precautionary measures.

\subsubsection{Salmonella infections in dogs, cats and humans}

3.2.3.1. The veterinary importance of Salmonella infections among dogs and cats A considerable number of Salmonella serotypes have been isolated from domestic dogs and cats around the world (Figure 1, Additional file 1: Table S1). The majority of infections are asymptomatic [146]. However, gastrointestinal disease manifested as enterocolitis and endotoxemia can occur and is often associated with fever, vomiting, anorexia, dehydration and depression [147-149]. Abortion, stillbirth, meningoencephalitis, respiratory distress and conjunctivitis have also been described [150,151]. Salmonella prevalence among dogs and cats appears variable and probably depends on a variety of factors. One study 
analyzed the apparent Salmonella prevalence among greyhounds on race tracks and found $43.5 \%$ of dogs were shedders, while another study described the apparent prevalence among racing Alaskan sled dogs at approx. $60 \%$, and the prevalence among stray dogs is likely equally high $[147,152-154]$. In general, however, the rate of shedding is thought to be much lower, and a number of studies on non-racing client-owned dogs and client-owned cats report shedding rates in the range of $1-5 \%$ [155-160].

Ingestion of contaminated food is thought to be the predominant risk factor. Salmonella has been isolated at high frequency from raw dog food on greyhound race tracks, and asymptomatic carriers developed after experimental oral inoculation, with shedding observed for periods of up to four weeks $[161,162]$. Dogs fed raw food diets appear to be at particular risk. Finley et al. [163] report that, in the absence of clinical signs, 50\% of dogs fed contaminated raw food diets shed Salmonella in their feces, while none of the control dogs fed Salmonella-free diets shed Salmonella. In another, longitudinal study, Joffe et al. [164] isolated Salmonella at least once from the feces of $80 \%$ of client-owned dogs fed a common bone and raw food (BARF) diet. Surprisingly, Salmonella was also isolated on one or more occasions from $30 \%$ of client-owned controls, which were fed commercial dog food. Some serotypes such as Salmonella Typhimurium, Heidelberg, and Kentucky appear to be predominantly isolated from dogs fed raw food diet, and one study estimated the odds of shedding Salmonella to be approx. 23 times greater for dogs fed raw food diets than commercial diets [165]. Asymptomatic carriers shed Salmonella intermittently, and longitudinal studies provide evidence for multiple coinfections during relatively short time periods [166].

3.2.3.2. The public health risk associated with Salmonella infection among dogs and cats A number of medically important serotypes for humans have been isolated from domestic dogs and cats (Figure 1, Additional file 1: Table S1), and several studies have reported the isolation of multidrug-resistant isolates (see [167] for a comprehensive review of the topic). Human Salmonella cases have been attributed to contact with infected dogs or cats at home or in veterinary clinics (Table 1). For instance, in 1938 the family dog was implicated as source of a human Salmonella Glostrup outbreak and in 1952 a human case of Paratyphi B was linked to direct dog contacts at home. In 1999 human outbreaks of Salmonella Typhimurium in Idaho and Washington were linked to contact with clinically ill kittens in veterinary clinics, and a human outbreak in Minnesota was linked to contact with cats from a shelter. A 2003 outbreak of Salmonella Typhimurium among humans in New York was also linked to a small animal veterinary clinic, but the index animal was not clearly identified. A recent case-control study of childhood salmonellosis in Michigan identified cat exposure, as well as reptile contacts, as risk factor for Salmonella infection, emphasizing the potential risk [168]. The risk posed to humans by indirect contact, for instance with excrement, is currently not clear. Infected humans also represent a possible source of infection for their animals. In addition, animal-to-animal spread occurs readily and has been clearly documented during a Salmonella outbreak in a military dog kennel [169]. In this instance, the index case acquired Salmonella through feed.

Together, these data indicate that contacts with dogs and cats in homes, veterinary clinics and shelters clearly represent potential threats to human health. Raw food diets are associated with a significantly higher prevalence of Salmonella than other pet food diets, and since asymptomatic shedding is common it appears that animals on such diets might be suspected of Salmonella shedding regardless of clinical symptoms. Especially if some household members are at a heightened risk of infection, or if animals are introduce into therapeutic settings, other feed types may be preferable. Salmonella represents a clear occupational hazard. Good hygiene practices, environmental infection control, strict quarantine procedures, personal protective equipment, and other biosecurity measures are therefore crucial to reduce the risk wherever dogs or cats are kept in large groups or subjected to high levels of stress.

\subsubsection{Commercial pet food and treats as sources of infection}

Salmonella contamination in pet foods and treats varies considerably by food type. Commercial raw food diets, representing combinations of raw meat, vegetables, grain and eggs or fruit, are available fresh or frozen in a large number of pet stores and veterinary clinics, and a recent Canadian study estimated Salmonella prevalence in these feeds to equal approx. 21\% [170]. Several Salmonella-related recalls of raw foods have been reported in recent years, for instance of frozen cat food in the USA in 2007. Contamination rates in dry or canned foods are thought to be considerably lower, and to our knowledge Salmonella has not been isolated from canned dog food, but the number of available studies is very limited $[8,9]$. Dry dog food has recently been linked to a large human salmonellosis outbreak, and dog and cat vitamins have been recalled due to Salmonella contamination, but prevalence data is currently scarce $[9,171]$. Dried pigs ears and a variety of other dried animal parts are commercially available as dog treats. Contamination rates in these commodities appear to be high. For instance, in 2001 a Canadian study reported isolating Salmonella from 50\% of pig ears and other 
animal-derived pet treats, and a 2003 study found $41 \%$ of animal derived pet treats sold commercially in the USA contaminated with Salmonella [172,173]. Isolates included Salmonella Typhimurium, Heidelberg, Anatum, Infantis, and Derby, and a considerable number of samples contained more than one serotype (Additional file 1: Table S1). Voluntary preventive measures implemented by the pet treat industry appear to have led to a considerable reduction in contamination rates, but a disease risk remains [174]. For instance, in December 2009, pig ears and beef hoof products were recalled in the USA because of a potential Salmonella contamination.

Exposure to commercial pet food and animal derived pet treats has also repeatedly led to human outbreaks (Table 1). For instance, in 2007 the CDC identified a multi-state outbreak of Salmonella Schwarzengrund linked to commercial dry pet foods, which affected dogs and their owners in 18 states of the USA and led to a nation-wide product recall. In 1999, pig ear treats contaminated with Salmonella Infantis led to a human outbreak of salmonellosis in Canada, and in 2002, pet treats contaminated with Salmonella Newport were responsible for human Salmonella infections in Canada. Salmonella outbreaks among humans have also been linked to rodents commercially sold as pet food, but these are more appropriately described in the section regarding rodents.

In conclusion, pet feeds represent a direct and indirect threat to human and animal health. The choice of pet food and treats can considerably influence the Salmonella risk for animals and humans, and might be of particular importance if high-risk human population subgroups are exposed at home or in therapy settings, or if animals are exposed to stressful situation such as in kennels, veterinary clinics or shelters. However, good hygiene practices such as hand washing before and after feeding, appropriate cleaning of bowls and contact surfaces, and adequate storage can probably decrease the direct risk for humans considerably.

\subsection{Rodents, rabbits and Salmonella}

\subsubsection{The clinical and environmental importance of Salmonella infections among rodents and rabbits}

Salmonella has repeatedly been isolated from wild mice and rats, which represent important reservoir hosts on farms and in food production environments (Additional file 1: Table S1). Prevalence estimates for wild or captive rodents are relatively scarce, variable among geographic regions, and the numbers of studies as well as the prevalence seem to have decreased over time. In general, Salmonella shedding rate estimates are in the range of 1 to 15\% [175-179]. Salmonella prevalence among captive rodents is low, and environmental reservoirs may play a paramount epidemiologic role [180]. Salmonella has also been isolated from pet rabbits, indicating a potential risk associated with this animal species [181]. However, the available prevalence data, especially for pet rabbits, is currently very scarce. Salmonella might to be fairly common in intensive rabbit meat production systems, with one study reporting that as many as $30 \%$ of intensive rabbit farms in Italy were positive for Salmonella [182]. However, a low prevalence of Salmonella among rabbit carcasses in Spanish slaughterhouses has also been reported, indicating that Salmonella prevalence among commercially farmed rabbits is probably variable [183].

Salmonella infection can cause severe disease in rabbits, which is sometimes associated with high mortality [182]. Clinical symptoms include enteritis, metritis and abortion, but striking differences in pathogenic potential seem to exist among different Salmonella serotypes [182]. In contrast, the majority of infections in mice and rats are asymptomatic. However, clinical disease among rodents has also been described, for instance during large outbreaks among laboratory rodents, which were associated with high mortality rates (Additional file 1: Table S1). Indeed, Salmonella Typhimurium and Enteritidis have been widely used as rodenticide in the first half of the $20^{\text {th }}$ century and continue to be used in some countries despite the public health risk [184,185]. Systemic disease appears to be the most common clinical manifestation in mice and rats, and mortality is predominantly attributable to septicemia [186]. Pathogenicity is age and host strain dependent, with the highest mortality rates observed in young animals under three weeks of age [187]. A number of serotypes with importance for humans have been isolated from wild, laboratory or pet rodents (Figure 1, Additional file 1: Table S1). Clinical Salmonella outbreaks among guinea pigs and hamsters, associated with conjunctivitis and soft tissue abscesses, have also been described [188,189]. 3.3.2. The public health importance of Salmonella infection among rodents and rabbits

In recent years, human outbreaks have repeatedly been associated with captive rodents sold in the USA as snake feed or pets (Table 1). For instance, in 2004 a large multi-state outbreak of Salmonella Typhimurium among humans was associated with hamsters, rats and mice sold in pet shops across the USA. Similarly, in 2005 and 2006, a multi-state outbreak of Salmonella Typhimurium among humans was linked to frozen rodents sold as commercial snake feed. Sporadic human cases have also been linked to rodent contact, for instance a human case of Salmonella Oranienburg attributable to contact with a clinically sick guinea pig. In conclusion, rodent contacts represent a direct and indirect threat to human health. Wild rodents can serve as source of human infection by contaminating feeds, food, 
water or the environment, and they can conceivably infect dogs, cats or other animals if ingested. Salmonellosis represents an occupational hazard for exterminators, rodent breeders, and others that professionally handle rodents. Rodents often show no or atypical signs of salmonellosis, thus clinical symptoms in animals are of limited diagnostic value. To our knowledge, data on zoonotic transmissions from rabbits is not available at the point of writing, likely at least in part due to underreporting of human salmonellosis cases. Contacts with sick or clinically healthy rodents or rabbits can potentially lead to human exposures, and the enforcement of good hygiene practices is important to minimize the risk for humans.

\subsection{The role of non-traditional mammalian pets and wildlife}

Non-traditional pets are captive-bred or wild-caught, endogenous or exotic animals held as pets that have not reached wide-spread popularity among pet owners and are therefore not commonly bred for human companionship [190]. Apart from reptiles, amphibians, and fish, non-traditional pets include a variety of mammalian species such as non-human primates, African pygmy hedgehogs, ferrets, prairie dogs, and sugar gliders $[190,191]$. Lack of husbandry expertise often results in stress, malnutrition or abandonment, and bites or scratches pose a considerable risk to pet owners [191].

\subsubsection{Exotic pets, wildlife and Salmonella}

Little is known about the prevalence, pathogenicity, and distribution of Salmonella among non-traditional mammalian pets or their wild relatives, but Salmonella has been isolated from a large number of wild mammals or their feces, including opossums, squirrels, woodchucks, raccoons, foxes, mink, cougars, tigers, wild boars, hippopotami, rhinoceroses, seals and whales (Figure 1, Additional file 1: Table S1). Serotypes with particular importance for human health have also been isolated from white-tailed deer feces in Nebraska, even though Salmonella prevalence in this species is believed to be quite low (Additional file 1: Table S1). One Norwegian study of Salmonella in feral hedgehogs reported prevalence estimates between 0 and $41 \%$, which varied considerably by geographic area [192]. High prevalence corresponded to human outbreaks in the same region, and isolates with identical PFGE patterns were isolated from wild hedgehogs and humans, potentially indicating an epidemiological link, which is also supported by an independent Danish study [193]. Salmonella prevalence among captive hedgehogs, sugar gliders and other nontraditional pets is currently unknown. Clinical disease associated with Salmonella infection has been described in sugar gliders and hedgehogs, but a large number of cases are believed to be asymptomatic [194,195].
Several human cases and outbreaks of serotypes Typhimurium and Tielene have been linked to pet hedgehog contacts (Table 1), and Salmonella Enteritidis and Sofia have also been isolated from hedgehogs kept as pets (Additional file 1: Table S1). Salmonella Tielene represents a very rare serotype. Human cases are strongly associated with hedgehog exposure, and children appear to be at heightened risk of infection [195]. Salmonella Tielene was first isolated in the USA in 1994 during a human outbreak associated with an African pygmy hedgehog breeding colony [195]. In Canada the geographic distribution of human Tielene cases starkly resembles that of pet hedgehogs, emphasizing the epidemiological role of this pet species [196]. Human Tielene outbreaks have also been linked to sugar glider exposure, indicating a role of this exotic pet in Salmonella Tielene epidemiology [196].

In conclusion, wildlife and exotic pets clearly represent potential sources of human infection, but relevant data is so far scarce. Salmonella can cause disease in these animals, but asymptomatic carriers appear to be common and likely also pose a considerable infection risk. Good hygiene practices and measures that reduce stress, such as adequate housing, nutrition and care, can likely reduce the risks associated with captive animals.

\section{Avian Sources of Human Salmonellosis 4.1. Overview of Salmonella infections in birds}

World-wide, birds are held for meat or egg production, companionship, sports, scientific or educational purposes. In 2007, an estimated 17.9 billion chickens, 1.1 billion ducks, 447 million turkeys and 343 million geese and guinea fowl were farmed world-wide [39]. Of these, approx. 9.4 billion chickens, 997 million ducks, 14 million turkeys and 307 million geese were farmed in Asia alone. In addition, a considerable number of animals are held as pets, with 6.4 million households in the USA alone owning pet birds [106].

\subsection{Salmonella infections among galliform birds}

Chickens, turkeys, quails, pheasants and other gamebirds are members of the order galliformes. Salmonella is common in galliform birds, and has been isolated at high rates from commercially reared chicken, turkeys, and other poultry (Figure 1, Additional file 1: Table S1). Apart from the associated foodborne risk, farms may represent a direct risk to public health, even though relevant studies are so far missing and high biosecurity standards in most commercial poultry productions probably minimize the risk.

The clinical symptoms associated with Salmonella infection vary considerably by age group and serotype [197]. Infections with generalist serotypes rarely cause 
clinical disease in galliform birds and most animals become asymptomatic carriers, even though severe clinical disease with high mortality has been observed in some instances, particularly during infections of young birds [198,199]. Infections with the host adapted serotype Gallinarum biovars Gallinarum and Pullorum, however, cause severe disease with high mortality and immense economic losses on chicken and turkey farms (see [200] for a review of the topic). Salmonella Gallinarum biovar Pullorum causes "Pullorum disease" in young animals, which is associated with septicemia and high mortality that can exceed $85 \%$ in some instances [197]. Salmonella Gallinarum biovar Pullorum infections of adult birds are generally mild or asymptomatic, even though decreases in fertility and egg production as well as increased mortality have been observed in some instances. Adult animals can develop a carrier state, and transovarian transmission is thought to be the primary rout of transmission to young birds, even though rodents and other vectors are also thought to play an important epidemiologic role (see for instance [201]). Clinical symptoms include anorexia, diarrhea, dehydration, decreased hatching, and high mortality. Salmonella Gallinarum biovar Gallinarum causes "fowl typhoid" in young and particularly adult birds [200]. Clinical symptoms are very similar to those observed during infections with biovar Pullorum, and economic losses during outbreaks can be very high. Both Gallinarum biovars Gallinarum and Pullorum are host restricted and therefore pose a negligible risk to human health. In contrast, infections with Salmonella Enteritidis are typically asymptomatic in adult birds but can cause systemic disease in young birds, and transovarian transmission of serotype Enteritidis has also been described [202]. Infections with Salmonella Enteritidis pose a considerable human health risk, and have been estimated to inflict costs of approx. 1 billion US dollar per year on the USA economy [203].

Salmonella prevalence varies considerably by poultry type, differs between serotypes and biovars, and intestinal carriage often appears to be lower than isolation rates from egg shells, dead birds, and environmental samples [204,205]. Salmonella prevalence in hatcheries is estimated between 0 and $17 \%$ for chickens, compared to approx. $25 \%$ for geese, and 20-60\% for ducks $[204,205]$. Salmonella Gallinarum biovars Pullorum and Gallinarum have been eradicated in commercial poultry productions in the developed world, but are still important in backyard flocks as well as the developing world [197]. It is conceivable that serotype Enteritidis filled the ecologic niche left by the eradication of serotype Gallinarum biovar Gallinarum, since a considerable increase in Enteritidis prevalence co-incided with the eradication of biovar Gallinarum in the 1960s (see [206] for a review of the subject). In fact, mathematical modeling results have suggested a potential role of competitive exclusion between serotypes Enteritidis and Gallinarum biovar Gallinarum in poultry [207]. Salmonella Enteritidis, as well as serotypes Typhimurium, Kentucky, and Heidelberg, are commonly detected among clinically healthy as well as sick chickens and turkeys, indicating a potentially important risk for human health (Figure 1, Additional file 1: Table S1).

A number of people raise chickens and other poultry in their backyards for meat, egg production or as pets [208]. In addition to household exposure, human cases have been linked to poultry contact on farms, in agricultural feed stores, and at country fairs [209]. Young hatchlings pose a particularly high risk for humans, and remarkably often infect children (Additional file 2: Table S2). The number of human outbreaks increases strikingly around Easter, when chicken or duck hatchlings are especially popular pets. Such outbreaks have been documented every few years since the 1950s (see for example [209-211]). To reduce the risk associated with hobby farming, the sale of poultry for meat or egg production at feed stores is prohibited in all USA states [212]. In addition, the USA CDC and some state health departments work to increase public awareness and to promote customer education at the store level. Some USA states have passed additional regulations, such as legislations restricting the minimum age of animals at sale or the maximum number of animals purchased per person [212]. However, enforcement of these laws is difficult and legislation varies among states [213]. The USA CDC has published recommendations regarding pet poultry, including that no children under the age of 5 handle baby poultry [214].

In conclusion, the human health hazards posed by pet poultry, and young hatchlings in particular, are substantial, but fairly well understood. The laws and recommendations provided by the USA CDC and comparable institutions can successfully mitigate the risks. However, public awareness and collaboration between governmental agencies, related industries, special interest groups, and the veterinary community is crucial to assure sustainable results. The risks of direct transmission to humans that are associated with commercial poultry productions are less well understood. Salmonella certainly poses an occupational risk to farmers, veterinarians and slaughterhouse employees, but whether commercial poultry farming poses direct risks to the general population remains yet to be determined.

\subsection{Salmonella infections among anseriform birds}

Ducks, geese and swans belong to the order Anseriformes. The majority of Salmonella infections in ducks appear to be asymptomatic, but severe clinical disease 
with high mortality has also been described [215]. Clinical disease is predominantly observed in young animals, and seems to generally be associated with environmental or management stressors. Common symptoms include anorexia, depression, diarrhea, dehydration, ataxia, opistothotonus, arthritis, and synoviatis, and decreases in fertility and hatching have also been reported [215].

The prevalence of Salmonella shedding appears to be species and age group dependent. Salmonella shedding is comparably common among commercially raised ducks and geese, yet highly variable across age groups. Salmonella Typhimurium, for instance, has been isolated from $40 \%$ of hatchlings and $1 \%$ of older ducklings in Taiwan, even though clear host species specific differences were also detected [216]. The prevalence of Salmonella shedding among wild birds appears to be quite variable (see for instance [217] for a review). Mitchell and Ridgwell, for instance, reported isolating Salmonella from approx. 4\% of bird droppings in London [218]. Conversely, Cizec et al. reported isolating Salmonella from $19 \%$ of wild gulls sampled in the Czech Republic [219]. However, lower prevalence estimates among gulls have also been reported in the literature, in the range of $3-13 \%$, and considerable differences between bird species and age groups seem to exist [219-221].

A number of human outbreaks have been linked to duckling exposure, and often both ducklings and chicken hatchlings are involved in the same outbreak, indicating great similarities in transmission and epidemiology (Additional file 2: Table S2). Analogous to chicken farms, it remains yet to be determined whether commercial duck and geese farms represent a substantial direct risk to human health. Similarly, the potential role of wild ducks and geese for human health is still subject to debate and conclusive evidence for or against an important role has yet to be presented (see [217] for a review of the subject). In conclusion, the risk associated with pet ducklings is high, but relatively well understood and bears great similarities to that observed for young chicken. Commercially reared or wild anseriform birds might conceivably pose a substantial risk to human health, but more data is needed before the subject can be evaluated conclusively.

\subsection{Salmonella infections among columbiform birds}

Doves and pigeons belong to the order of columbiform birds. Upon Salmonella infection, most adult birds show no or mild signs of disease, but severe paratyphoid disease with high mortality has been reported among young birds [222]. Clinical manifestations are variable and include gastro-enteritis, growth retardation, anorexia, depression, fever, torticollis, opisthotonos, oophoritis or orchitis, arthrosynovitis, and abscesses. While a variety of serotypes have been isolated from pigeons and doves, Salmonella Typhimurium var. Copenhagen phage types 2 and 99 are the most commonly isolated subtypes [223]. Intriguingly, the Typhimurium isolates from pigeons differ biochemically and antigenically from other Typhimurium isolates, likely indicating host adaptation of these Typhimurium subtypes to pigeons [217,222,223].

Salmonella appears to be a relatively common pathogen among pigeons and doves, but the prevalence seems to differ by serotype and habitat (see [217] for a review of the subject). Petersen [224], for instance, compared Salmonella prevalence in wild pigeons from urban areas and dairy farms in Colorado, and detected Salmonella in approx. $8 \%$ of samples from dairy-exposed pigeons but not in samples from pigeons in urban areas. However, the isolation of various Salmonella serotypes from wild pigeons in urban areas in Japan has also been reported, indicating a potential risk for human health [225]. Endemic infections among domestic pigeons in lofts have been described, and prevalence estimates of 25-30\% within individual lofts have been reported [217]. Salmonella Typhimurium var. Copenhagen phage types 2 and 99 seem to be the predominant serotypes among domestic pigeons, but other serotypes have also been isolated [217].

In conclusion, Salmonella appears to be relatively common among pigeons. However, most infections seem to be due to host adapted subtypes of Typhimurium, and therefore likely only pose a limited risk to humans. In fact, to our knowledge, no zoonotic transmission from pigeons to humans has been documented in the literature, even though underreporting of human cases likely contributed to this lack of observation. Salmonella can also be found in wild doves, probably mostly at low prevalence. Broad-spectrum serotypes have been isolated from wild pigeons and environmental contamination appears to represent an important risk factor for shedding in doves and pigeons, indicating that such birds may represent potentially important vectors on livestock premises and possibly carry some direct risk for humans.

\subsection{Salmonella infections among passerine birds, psittacine birds, and other non-domesticated birds} Passerine birds are commonly referred to as songbirds, while psittacine birds include parrots, cockatoos and parakeets. Both passerine and psittacine species are not only important wild bird species, but also represent popular pets and are often kept in zoological exhibits. Numerous Salmonella serotypes have been isolated from a variety of captive birds held as pets (Figure 1, Additional file 1: Table S1). Acute and chronic infections have been reported, which range from asymptomatic to clinically severe and can manifest as diarrhea, 
anorexia, dehydration, depression, crop stasis, septicemia or osteomyelitis [226-228]. For instance, Salmonella has been isolated from pet shop and household birds in Trinidad, imported finches, lories and parakeets in Japan, a variety of captive birds imported into Britain, numerous psittacine species held in Brazil, psittacine pet birds in Texas, Tennessee and Kansas, and captive as well as free-ranging parrots in Bolivia (Additional file 1: Table S1). Salmonella outbreaks with high bird mortalities have been described in zoologic exhibits, captive bird colonies and falcon collections [229-231].

Captive birds can also pose a Salmonella risk to humans, even though only a very limited number of cases have been documented (Additional file 2: Table S2). For instance, parakeets were involved in the transmission of Salmonella Typhimurium to a human infant and a cat, even though the exact transmission routes were not clearly determined [232].

Asymptomatic Salmonella carriage in wild birds is thought to be high, and wild birds have repeatedly been implicated as vehicles on farms and in feed mills [233-236]. Around the world, a variety of serotypes, including those frequently isolated from humans, have been isolated from free-ranging songbirds, parrots and parakees, with clinical manifestations ranging from asymptomatic to peracute death (Figure 1, Additional file 1: Table S1). Stress increases the risk of shedding, and in songbirds salmonellosis commonly peaks in winter months, likely due to crowding and increased contact rates at bird feeders [237]. Salmonella prevalence among birds at feeders is commonly higher than in the general population, and epidemics have been reported repeatedly, for example during the winter of 1997/98, when an epidemic affected songbirds across the eastern parts of North America [237-239].

Wild songbirds have also been repeatedly implicated as source of human infection (Additional file 2: Table S2). For instance, during the winter of 2000, Typhimurium isolates with identical Pulsed Field Gel Electrophoresis (PFGE) patterns were associated with a Salmonella outbreak among wild birds as well as human cases in New Zealand, and an epidemiologic link, potentially due to contaminated water, appears plausible [239,240]. Evidence also suggests that a large number of human Typhimurium cases in Norway were associated with wild bird contacts [241]. Other non-domesticated birds also potentially pose a risk to human health. In 2001 an elementary school Typhimurium outbreak involving at least 40 human cases was linked to dissecting owl pellets collected from captive owls, and more recently another outbreak in Massachusetts was also linked to owl pellets [242].

In conclusion, contacts with wild or captive birds pose a possible threat to human health, even though many epidemiological details remain to be understood. Birds, bird droppings, pellets, and feathers, as well as contaminated water and environments represent a potential risk.

\section{Reptiles, Amphibians and Fish as Sources of Human Infection}

Contact with reptiles, amphibians or pet fish also represents an important source of Salmonella infection (Additional file 2: Table S3). Reptiles, amphibians and fish have become popular pets in many countries. For example, approx. $3 \%$ of households in the USA own one or more reptiles as pets, resulting in a total of approx. 7.3 million reptiles [106]. The number of pet turtles has doubled in recent years, and in the USA approx. 2 million turtles are now kept in over 1 million households. More than 400000 USA households keep snakes and in excess of 700000 households own lizards [106]. Pet fish are present in an estimated 15 million USA households, with approx. 0.8 million households owning salt water fish tanks [191]. An estimated 1.3 million reptiles and 203 million fish were imported legally into the USA in 2005 alone, and a considerable number of pets are imported illegally each year [191]. Imports include captive-bred as well as wild-caught animals and the exotic pet trade poses a potential public health threat [191].

\subsection{Reptiles and Salmonella}

\subsubsection{Salmonella prevalence and serotype diversity among reptiles}

Salmonella occurs naturally in the gastrointestinal tract of many reptiles, is commonly shed by these animals, and around the world a large number of serotypes have been isolated from feral and captive reptiles as well as their eggs (Figure 1, Additional file 1: Table S1). Clinical disease, including septicemia, osteomyelitis, salpingitis, nephritis, dermatitis and abscesses, seems to be occasionally associated with Salmonella infection in snakes, turtles, and lizards, but the overwhelming majority of infections in reptiles are undoubtedly asymptomatic; clinical salmonellosis in reptiles is rare, appears to be associated with underlying disease or other stressors, and a causal relationship between Salmonella infection and disease is generally difficult to establish conclusively [243-245]. Whether Salmonella infection causes diarrhea in reptiles is still subject to debate, and might depend on a variety of factors including host species and ambient temperature during infection [246,247]. For instance, links between a case of necrotizing gastritis in a snake and Salmonella infection or between atrophic gastritis in a tortoise and Salmonella has been suggested, but so far reports are predominantly anecdotal (see for instance [248] for a review).

Prevalence estimates in free-ranging reptiles vary widely, and a few studies report the absence of 
Salmonella in their study populations [249,250]. Prevalence estimates in other studies range from 6 to $100 \%$ in turtles, from 30 to $76 \%$ in lizards and from 54 to $100 \%$ in snakes [251-257]. It has been estimated that as many as $90 \%$ of all captive reptiles carry Salmonella, including a large number of 'reptile-associated' as well as "broad host-range" serotypes [196,246]. Some studies have investigated the efficacy of antimicrobial treatments, sometimes combined with physical treatments, in reducing reptile Salmonella carriage, and initial laboratory experiments proved promising [258-260]. However, the routine treatment of reptiles, eggs, or pond water on commercial farms is complicated by farming conditions, intermittent Salmonella shedding, transovarian infections, coprophagy, and environmental reservoirs, and these treatments appear to be associated with a heightened risk of antibiotic resistance [261-264]. Salmonella has been isolated from commercially raised turtles, crocodiles, alligators, and iguanas, their meat, or the farm environment, and contamination levels appear to be substantial, with prevalence estimates for farmed turtles as high as $40 \%$ (Additional file 1: Table S1). The stress of transportation and the close physical contact during transport may further contribute to Salmonella shedding, especially among baby turtles and lizards.

\subsubsection{The risk associated with contacts to reptiles}

Human salmonellosis attributable to reptile exposure was first documented in the 1940s, and a large number of case reports have since described zoonotic transmissions of Salmonella from reptiles to humans (Additional file 2: Table S3). The exact number of reptile-associated salmonellosis cases among humans is difficult to determine, but one study estimated that in the USA, reptile exposure contributes approx. 70000 human cases each year [265]. This represents $6 \%$ of all sporadic human cases, and reptile-associated cases are estimated to contribute $11 \%$ of sporadic human cases in the population $<21$ years of age [265]. In the European Union, apparent prevalence estimates vary considerably among member states and over time [266]. In Sweden, for instance, 339 human reptile associated cases have been reported between 1990 and 2000, equaling approx. 5\% of reported human cases [266,267]. This number increased markedly in subsequent years until a public education campaign was launched in 1997 [267].

A large number of human salmonellosis cases have been linked to contact with turtles, terrapins, snakes, and lizards such as iguanas, bearded dragons, geckos, and chameleons (Additional file 2: Table S3). Reptileassociated Salmonella infections in humans tend to be more likely associated with systemic disease than foodborne infections. Especially among children, the elderly or pregnant women, septicemia, meningitis, arthritis, soft-tissue abscesses, osteomyelitis, pericarditis, myocarditis, peritonitis and urinary tract infections have been repeatedly described, leading to severe disease and comparably high mortality rates (Additional file 2: Table S3). However, frequently only a single person or household is affect, and many reported cases involve children and infants. The reasons for the high prevalence among infants and children are not clear and might include biological, immunological and behavioral determinants $[268,269]$. Few reptile owners are aware of the disease risk. In the USA, the CDC recently reported that only approx. $20 \%$ of interviewed human cases were aware of the link between reptiles and Salmonella [269]. Good hand hygiene, which has been shown to be a very effective measure to prevent infection, may therefore not be strictly enforced [270].

Salmonella survives over long time periods in the environment, and a number of human outbreaks have been attributed to indirect reptile contact (Additional file 2: Table S3). Reptile-associated salmonellosis occurs frequently in small children, which are rarely allowed direct contact with snakes or lizards, strongly suggesting indirect exposure routes (Additional file 2: Table S3). In fact, a case-control study found presence of reptiles in the home to be a highly significant risk factor for salmonellosis in infants $<1$ year of age, strongly suggesting a predominant role of indirect transmission [271,272]. In other cases, the evidence is even more compelling. For instance, in 1996 a human Salmonella outbreak with at least 65 cases was linked to contact with a wooded barrier around a Komodo dragon habitat in the Colorado zoo [270]. In 1994, hospitalized infants were infected with Salmonella Kintambo [271]. One infant's family owned a lizard which shed Kintambo and the infant's mother reported diarrheal illness shortly before giving birth, potentially indicating prior infection. In 2001, Salmonella Nima was isolated from a sick infant and a boa at the school where the infant's father worked [273]. The father reported carefully washing his hands after handling the snake or its container, but frequently draped the snake around his arm and did not change his clothes before handling the infant. In 2004, Salmonella Typhimurium was isolated from an 80 year old woman and the bowl in which her daughter's turtle was kept [274]. The women had no direct contact with the turtle or its bowl, but the bowl was cleaned in the kitchen sink. Given the large number of indirect transmissions, the USA CDC recommends that households with young children (i.e. $<5$ years of age) do not own reptiles and that reptiles are not introduced into school settings. Several organizations have published information materials and recommendations concerning pet reptiles. In the USA, these include for instance governmental organizations such as the CDC and FDA, as well 
as professional organizations such as the American Veterinary Medical Association, the Association of Reptile and Amphibian Veterinarians, and the National Association of State Public Health Veterinarians (NASPHV). However, despite intense efforts awareness has remained limited.

Given the high prevalence of Salmonella among feral alligators, crocodiles, turtles, and lizards, contamination of surface water, ponds and other natural surfaces also represents a potential public health concern, but quantitative risk estimates are currently not available [275-279]. At least two human cases have been linked to reptile-contaminated surface water. In this instance, pet turtles were allowed to swim in a non-chlorinated in-ground pool frequented by the two human case patients [269].

In conclusion, direct or indirect exposures to reptiles clearly represent a substantial risk to human health. Infants and young children are at a particularly high risk, and severe clinical manifestations seem common. A considerable fraction of cases occur due to indirect contacts. Moreover, the prevalence of Salmonella shedding among captive reptiles is high, and clinical symptoms are rare. Large parts of the general population may therefore be affected. Legislative efforts have achieved substantial successes in reducing the risk of reptileacquired infection. However, regulations have to be integrated with public education to achieve maximum compliance. Governmental agencies and several stakeholder groups work to increase consciousness. However, despite long-standing efforts, awareness of the Salmonella risk has remained comparably low. A number of alternative exposure routes can also lead to reptileassociated infections, and should be taken into consideration as appropriate.

\subsubsection{Salmonella - related regulations of pet turtle commerce}

Up to the 1970s, pet turtles represented a major source of salmonellosis in the USA, annually contributing an estimated 14 to $23 \%$ of salmonellosis cases among children [280,281]. This prompted numerous state governments to mandate certification of Salmonella free status for all locally sold pet turtles, and since 1972 the USA FDA required similar certifications for all pet turtles sold in interstate commerce [281]. When these measures proved ineffective, the FDA posed a nation-wide ban on the sale and distribution of turtle eggs and small turtles with shells less than 4 inches $(10.2 \mathrm{~cm})$ in diameter in 1975 [281]. This legislation markedly decreased the number of reptile-associated cases, and has been estimated to prevent approx. 100000 cases of salmonellosis, predominantly among young children, each year [281]. However, the ban did not prevent the sale of young turtles in all cases. Turtles less than 4 inches were still allowed to be sold for scientific, educational and exhibitional purposes, for export, or for purposes other than business, and the ban did not include marine turtles. In addition, small turtles were still illegally sold in pet stores and at unregulated vendors such as flea markets, and small turtles with shell diameters below 4 inches were still implicated in a considerable number of reptile-associated salmonellosis cases after the sale ban was enacted in 1975 (see for example [269,282]). In 2007, Louisiana Congressmen proposed the "Domestic Pet Turtle Market Access Act of 2007" to the US Senate, which aimed to overrule the sales ban if the seller met certain regulations regarding licensing, sanitization and consumer information. The specified reasons included the fact that the sale of lizards, snakes, frogs and other amphibians and reptiles as pets is not regulated by the FDA, even though they are known to carry Salmonella, and that Salmonella treatment technologies have advanced since the ban was initiated in 1975. The bill was referred to the Senate committee on agriculture, nutrition and forestry, but had no action taken and never passed.

\subsection{Amphibians and Salmonella}

The prevalence of Salmonella among amphibians seems to vary considerably by host species, even though the number of studies that analyze Salmonella shedding by amphibians is quite limited. Salmonella has frequently been isolated from frogs and toads, in which Salmonella infection seems to be predominantly asymptomatic (see for instance $[253,283,284])$. The prevalence of Salmonella among salamanders and newts appears to be lower than among frogs and toads, but the available data is currently relatively limited [283].

Contacts with toads or frogs clearly pose a potential risk to humans. In 2009, for instance, an outbreak of Salmonella Typhimurium, which affected people in more than 30 USA states, was associated with African dwarf frogs (Additional file 2: Table S3) [285]. Implicated frogs were traced back to a breeder in California, and Typhimurium isolates with PFGE patterns matching the outbreak strain were isolated from several environmental samples taken in the implicated breeding facility. In 2001 an outbreak of Salmonella Javiana in Mississippi was epidemiologically linked to contact with frogs and toads, even though the Salmonella serotype was not isolated from amphibians sampled during the outbreak investigation [286]. In 2000, frogs were epidemiologically implicated as the source of water contamination at a construction site in Australia, but no microbiological investigations of the frogs were performed [287]. Moreover, a case-control study estimated that the odds of Salmonella serogroup B or D infection among people < 21 years of age were 2.9 (95\% Confidence Interval: 1.5- 
5.8) times higher if amphibians were present in the household, again indicating a potential risk posed by these animal exposures [265].

\subsection{Fish and Salmonella}

Some studies have investigated the prevalence of Salmonella among wild, pet or farmed fish in different ecological niches, sometimes with somewhat conflicting results. Gaetner et al. [288], for instance, reported isolating Salmonella from 17-33\% of fish sampled in the San Marcos river in Texas and Miruka et al. [289] isolated Salmonella from approx. 31\% of fish samples collected in Lake Victoria, Kenya. Broughton and Walker [290], however, estimated the Salmonella prevalence among farmed fresh-water fish in China at approx. 5\%, and estimates for fish in retail markets in India have ranged from $10-28 \%$ [291].

Clinical disease associated with Salmonella infected fish have been described, mainly manifested as septicemia [292]. Yet, fish can also shed Salmonella in the absence of clinical signs, and after experimental inoculation of silver carp, shedding has been observed for periods of up to 14 days [293]. Fish feed appears to represent a considerable source of Salmonella infection in commercial aquacultures, and frequent bacterial carriage in raw materials paired with insufficient heat treatment appears to be the major driver [294].

\subsubsection{The risk associated with contacts to fish}

A variety of Salmonella serotypes have been isolated from free-ranging or captive fish (Additional file 1: Table S1), and Salmonella is common in wild and, probably to a lesser extent farmed, fish. Occupational infections have been linked to contacts with contaminated fish, and ornamental fish tanks have also been linked to human Salmonella outbreaks (Additional file 2: Table S3). An Australian study, for instance, reported that $82 \%$ of human cases during a Salmonella Java outbreak had been directly or indirectly exposed to exotic fish tanks, and the outbreak strain was detected in implicated tanks [295]. Surprisingly, clinical disease in fish was observed in a large number of tanks, indicating a high pathogenic potential in the fish [295]. In conclusion, exposure to pet, wild or farmed fish represents a potential risk to humans, but the data available regarding infections acquired through contact with fish is currently scarce.

\section{Invertebrates and Salmonella}

Salmonella has been isolated from a large number of insects and worms including ants, flies, cockroaches, mealworms and mosquitoes (Additional file 1: Table S1). However, almost nothing is known about the pathogenic potential of Salmonella in invertebrates. Salmonella-induced mortality in butterflies and Caenorhabditis elegans has been described, and it appears likely that Salmonella can induce disease in other invertebrates [296,297]. Whether Salmonella can survive metamorphosis is equally unclear and results might be partially serotype, environment, and host dependent (see [298] for a review of the topic). In general, Salmonella intestinal carriage decreases sharply during pupation, likely due to major changes in the gut environment, and competition with other gut microorganisms such as Proteus has been shown to effectively suppress Salmonella growth in flies [298]. The public health relevance of insects might therefore depend on the life stage, the breeding environment and the insect species, and some insects apparently represent more competent hosts than others [298]. Insects and worms have been proposed as disease vectors for Salmonella on farms, agricultural fields and in households; invertebrates have been associated with Salmonella transmissions between animal feeds; biting mites have been shown to efficiently transmit Salmonella to chickens, and house flies have been implicated as Typhoid fever vectors in military camps (Additional file 1: Table S1). Moreover, insects can represent reservoir hosts, and therefore may play pivotal roles in Salmonella persistence.

\section{Animal Contact in Public Settings as Source of Human Infection}

7.1. Human outbreaks linked to animal contacts in public settings

Salmonella has repeatedly been isolated from captive and domestic animals held in public settings. For instance, a Korean study sampling clinically health zoo animals reported isolating Salmonella from approx. $6 \%$ of animals, including 30\% of reptiles, $7 \%$ of birds and $1 \%$ of mammals [299]. Other studies report the isolation of Salmonella Dublin from a clinically healthy tiger at a zoo in the UK, from large cats and rodents in a zoo in India, from rhinoceroses in an animal park in the USA, from a newborn moose and an iguana in a zoo in Canada, from approx. $6.5 \%$ of animals in a zoo in Trinidad and from two animals in Swiss petting zoos (Additional file 1: Table S1). Salmonella has also been isolated from environmental surfaces in zoological gardens [300]. The health threat is aggravated by risky behaviors. For instance, one recent study found that $87 \%$ of visitors in Tennessee petting zoos had contact with potentially contaminated surfaces, and $74 \%$ had direct animal contact, but only $38 \%$ used hand sanitizer, while $49 \%$ had hand-toface contacts with $22 \%$ eating or drinking in animal contact areas [301].

Animal contact in public settings therefore represents another source of human infection, and direct or indirect animal contacts in petting zoos, zoological parks, 
country fairs, or other settings represent threats to public health [190]. As mentioned above, in 1996, for instance, 65 children became sick after visiting the Denver zoo, due to indirect contact with a Komodo dragon [270]. In 1991, a visit to a science center in Washington was associated with 5 human salmonellosis cases, in 2000, at least 18 people were affected by a Salmonella outbreak linked to a petting zoo in Ohio, in 2001, at least 19 salmonellosis cases were linked to animal contact at an agricultural exhibit in Alberta, Canada, in 2003, at least 17 human Salmonella cases were linked to contact with a wallaby in a public setting in Michigan, and in 2005, 19 human cases were linked to direct or indirect contact with pigs in a public setting in Wiscon$\sin [34,302,303]$.

In conclusion, animal contacts in public settings represent a Salmonella risk to occupationally exposed subpopulations as well as the general public, but management practices can effectively reduce the risk. To minimize risks, several governmental agencies have passed legislations governing animal exhibitions, and governmental as well as professional organizations have published related recommendations.

\subsection{Current legislation and recommendations: case study USA}

Minimizing the risk of disease transmission in public settings is a major concern for governments and professional organizations around the world. As one example, recommendations and legislation in the USA will be described in the following passage. The USA National Association of State Public Health Veterinarians (NASPHV), in conjunction with the CDC, published recommendations to prevent disease outbreaks in public settings, which are regularly updated. The recommendations are addressed to governmental agencies, educational settings, exhibit managers, veterinarians, caregivers, and visitors at particular risk of infection. The main focuses are on disseminating information, enhancing oversight and outbreak investigations, encouraging good hygiene practices, improving facility design, implementing disease monitoring and prevention systems, and prohibiting high risk contacts. To further address the threat, the CDC, the Association for Professionals in Infection Control and Epidemiology, the Animal-assisted Interventions Working Group and the NASPHV published a number of additional recommendations and the Association for Zoos and Aquariums has developed a certification program. Depending on the animal species, animal exhibits may also be subject to USDA inspections under the Animal Welfare act, but human disease risks are not explicitly addressed in these inspections. In addition, some states have passed additional legislations. For instance, North Carolina requires all animal exhibits with public access to obtain a license, Pennsylvania mandates minimum standards for exhibit sanitation, and Virginia requires a permit for the exhibition of wild animals. The relative effectiveness of these diverse mitigation strategies largely remains to be determined.

\section{Conclusions}

In conclusion, contact with animals is responsible for a number of human salmonellosis cases each year. A number of transmissions occur in the home, but others are occupational or related to public exposures in zoological gardens, schools, or state fairs. Infected animals can present with a great variety of clinical symptoms, and risk factors for transmission to humans clearly differ by animal species, age groups, animal purpose, and geographic region. However, some commonalities are clearly evident. Stress, concomitant disease, and contaminated feed represent universal risk factors for animal infection. Conversely, public awareness and proper hygiene practices are efficient measures to mitigate risks. In fact, frequent hand washing alone could likely prevent a substantial number of human infections each year. However, awareness of the risks is low and the collaboration between governmental agencies, professional organizations and special interest groups is necessary to resolve the problem. In some instances, new legislations or public awareness campaigns have led to dramatic decreases in Salmonella incidence. Yet, much remains to be done to safeguard public health and many aspects of Salmonella epidemiology remain to be discovered. Salmonella serotypes differ in host range and distribution among host species, but our understanding of the molecular and evolutionary determinants of these host range differences is still limited and the public health implications are currently difficult to assess. In summary, the risks associated with animal contacts are diverse and much remains to be uncovered, but we already posses important clues to manage the risks.

\section{Additional material}

Additional file 1: Table S1. Overview of Salmonella serotypes isolated from animals in different geographic regions.

Additional file 2: Table S2. Documented reports of Salmonella transmission from birds to humans available in the peer-reviewed literature or otherwise published by public health agencies. Table S3. Documented reports of Salmonella transmission from reptiles, amphibians fish to humans available in the peer-reviewed literature or otherwise published by public health agencies.

\section{Acknowledgements}

We thank Dr Kevin Cummings, Cornell University, for helpful comments and suggestions. Support for this project was provided by the National Institute of Allergy and Infectious Diseases, National Institutes of Health, Department of Health and Human Services, under Contract N01-Al-30054-ZC-006-07. K 
Hoelzer was supported by Morris Animal Foundation Fellowship Training Grant D08FE-403.

\section{Authors' contributions}

$\mathrm{KH}, \mathrm{MW}$ and AIMS conceived and outlined the study. $\mathrm{KH}$ and AIMS reviewed the pertinent scientific literature and collated references and tables. $\mathrm{KH}$ drafted the manuscript. All authors have read and approved the final manuscript.

\section{Competing interests}

The authors declare that they have no competing interests.

Received: 2 June 2010 Accepted: 7 September 2010

Published: 14 February 2011

\section{References}

1. Majowicz SE, Musto J, Scallan E, Angulo FJ, Kirk M, O'Brien SJ, Jones TF, Fazil A, Hoekstra RM: The global burden of nontyphoidal Salmonella gastroenteritis. Clin Infect Dis 2010, 50(6):882-889.

2. Voetsch AC, Van Gilder TJ, Angulo FJ, Farley MM, Shallow S, Marcus R, Cieslak PR, Deneen VC, Tauxe RV: FoodNet estimate of the burden of illness caused by nontyphoidal Salmonella infections in the United States. Clin Infect Dis 2004, 38(Suppl 3):S127-134.

3. Mead PS, Slutsker L, Dietz V, McCaig LF, Bresee JS, Shapiro C, Griffin PM, Tauxe RV: Food-related illness and death in the United States. Emerg Infect Dis 1999, 5(5):607-625.

4. Chalker RB, Blaser MJ: A Review of Human Salmonellosis: III. Magnitude of Salmonella Infection in the United States. Rev Infect Dis 1988, 10(1):111-124

5. EFSA (European Food Safety Authority): Scientific Opinion of the Panel on Biological Hazards on a request from the European Commission on a quantitative microbiological risk assessment on Salmonella in meat: Source attribution for human salmonellosis from meat. The EFSA Journal 2008, 625:1-32.

6. Lanzieri G: Population in Europe 2007: first results. Eurostat Statistics in focus 2008, 81.

7. CDC (Centers for Disease Control and Prevention): Preliminary FoodNet data on the incidence of infection with pathogens transmitted commonly through food - 10 states. MMWR Morb Mortal Wkly Rep 2009, 59(14):418-422.

8. D'Aoust JY: Salmonella in commercial pet foods. Can Vet J 1978 19(4):99-100.

9. CDC (Centers for Disease Control and Prevention): Update: recall of dry dog and cat food products associated with human Salmonella Schwarzengrund infections-United States, 2008. MMWR Morb Mortal Wkly Rep 2008, 57(44):1200-1202.

10. Doyle ME, Kaspar C, Rachel Klos JA: White paper on human illness caused by Salmonella from all food and non-food vectors. FRI Briefings 2009 [http://fri.wisc.edu/docs/pdf/FRI_Brief_Salmonella_Human_Illness_6_09.pdf].

11. Economic Research Service, USDA (United States Department of Agriculture): Foodborne Illness Cost Calculator. 2010 [http://www.ers.usda. gov/data/foodborneillness/], [on line]

12. Ivanek R, Grohn YT, Tauer LW, Wiedmann M: The cost and benefit of Listeria monocytogenes food safety measures. Crit Rev Food Sci Nutr 2004, 44(7-8):513-523.

13. Uzzau S, Brown DJ, Wallis T, Rubino S, Leori G, Bernard S, Casadesus J, Platt DJ, Olsen JE: Host adapted serotypes of Salmonella enterica. Epidemiol Infect 2000, 125(2):229-255.

14. Baumler AJ, Tsolis RM, Ficht TA, Adams LG: Evolution of host adaptation in Salmonella enterica. Infect Immun 1998, 66(10):4579-4587.

15. Smith HW, Jones JE: Observations on experimental oral infection with Salmonella dublin in calves and Salmonella choleraesuis in pigs. J Pathol Bacteriol 1967, 93(1):141-156.

16. Olsen JE, Skov M: Genomic lineage of Salmonella enterica serovar Dublin. Vet Microbiol 1994, 40(3-4):271-282.

17. Gyles CL: Pathogenesis of bacterial infections in animals. Ames, lowa: Blackwell Pub; 32004

18. Kingsley RA, van Amsterdam K, Kramer N, Bäumler AJ: The shdA gene is restricted to serotypes of Salmonella enterica subspecies I and contributes to efficient and prolonged fecal shedding. Infect Immun 2000, 68(5):2720-2727.
19. Vargas-Galindo Á: Probabilistic inversion in priority setting of food borne pathogens. MSc thesis, Delft University of Technology, Department of Applied Mathematics and Risk Analysis 2007.

20. Wegener HC: Danish initiatives to improve the safety of meat products. Meat Sci 84(2):276-283.

21. Magnino S, Colin P, Dei-Cas E, Madsen M, McLauchlin J, Nockler K, Maradona MP, Tsigarida E, Vanopdenbosch E, Van Peteghem C: Biological risks associated with consumption of reptile products. Int J Food Microbiol 2009, 134(3):163-175.

22. Hanning IB, Nutt JD, Ricke SC: Salmonellosis Outbreaks in the United States Due to Fresh Produce: Sources and Potential Intervention Measures. Foodborne Pathog Dis 2009, 6(6):635-648.

23. Gantois I, Ducatelle R, Pasmans F, Haesebrouck F, Gast R, Humphrey TJ, Van Immerseel F: Mechanisms of egg contamination by Salmonella Enteritidis. FEMS Microbiol Rev 2009, 33(4):718-738.

24. Padungtod P, Kadohira M, Hill G: Livestock production and foodborne diseases from food animals in Thailand. J Vet Med Sci 2008, 70(9):873-879.

25. Cahill SM, Wachsmuth IK, Costarrica ML, Embarek PKB: Food Safety: Powdered Infant Formula as a Source of Salmonella Infection in Infants. Clin Infect Dis 2008, 46(2):268-273.

26. Lammerding AM: Modeling and risk assessment for Salmonella in meat and poultry. J AOAC Int 2006, 89(2):543-552.

27. Bowen A, Fry A, Richards G, Beuchat L: Infections associated with cantaloupe consumption: a public health concern. Epidemiol Infect 2006 134(4):675-685.

28. Dalton CB, Gregory J, Kirk MD, Stafford RJ, Givney R, Kraa E, Gould D: Foodborne disease outbreaks in Australia, 1995 to 2000. Commun Dis Intell 2004, 28(2):211-224.

29. De Buyser ML, Dufour B, Maire M, Lafarge V: Implication of milk and milk products in food-borne diseases in France and in different industrialised countries. Int J Food Microbiol 2001, 67(1-2):1-17.

30. van Belkum A, Tassios PT, Dijkshoorn L, Haeggman S, Cookson B, Fry NK, Fussing V, Green J, Feil E, Gerner-Smidt P, Brise S, Struelens M: Guidelines for the validation and application of typing methods for use in bacterial epidemiology. Clin Microbiol Infect 2007, 13(Suppl 3):1-46.

31. Wells EV, Boulton M, Hall W, Bidol SA: Reptile-associated salmonellosis in preschool-aged children in Michigan, January 2001-June 2003. Clin Infect Dis 2004, 39(5):687-691.

32. Ackman DM, Drabkin P, Birkhead G, Cieslak P: Reptile-associated salmonellosis in New York State. Pediatr Infect Dis J 1995, 14(11):955-959.

33. Bender JB, Shulman SA: Reports of zoonotic disease outbreaks associated with animal exhibits and availability of recommendations for preventing zoonotic disease transmission from animals to people in such settings. J Am Vet Med Assoc 2004, 224(7):1105-1109.

34. Steinmuller N, Demma L, Bender JB, Eidson M, Angulo FJ: Outbreaks of enteric disease associated with animal contact: not just a foodborne problem anymore. Clin Infect Dis 2006, 43(12):1596-1602.

35. Lazarus R, Waghorn D, Nash C: Cutaneous Salmonella infection. Scand J Infect Dis 2007, 39(3):257-258.

36. Hendriksen SW, Orsel K, Wagenaar JA, Miko A, van Duijkeren E: Animal-tohuman transmission of Salmonella Typhimurium DT104A variant. Emerg Infect Dis 2004, 10(12):2225-2227.

37. FAO (Food and Agricultural Organization of the United Nations): FAOSTAT. 2010 [http://faostat.fao.org/site/291/default.aspx]

38. Steinfeld H, Gerber P, Wassenaar T, Castel V, Rosales M, de Haan C: Livestock's long shadow - environmental issues and options. Rome, Italy: FAO (Food and Agricultural Organization of the United Nations); 2006.

39. Tomley FM, Shirley MW: Livestock infectious diseases and zoonoses. Philos Trans R Soc Lond B Biol Sci 2009, 364(1530):2637-2642.

40. Rushton J: The economics of animal health and production. Cambridge, MA: CABI International; 2009.

41. Giles N, Hopper SA, Wray C: Persistence of $S$. typhimurium in a large dairy herd. Epidemiol Infect 1989, 103(2):235-241.

42. Huston CL, Wittum TE, Love BC: Persistent fecal Salmonella shedding in five dairy herds. J Am Vet Med Assoc 2002, 220(5):650-655.

43. Vanselow BA, Hum S, Hornitzky MA, Eamens GJ, Quinn K: Salmonella Typhimurium persistence in a Hunter Valley dairy herd. Aust Vet J 2007, 85(11):446-450.

44. Wray C, Wadsworth QC, Richards DW, Morgan JH: A three-year study of Salmonella Dublin infection in a closed dairy herd. Vet Rec 1989, 124(20):532-537. 
45. Brackelsberg CA, Nolan LK, Brown J: Characterization of Salmonella dublin and Salmonella typhimurium (Copenhagen) isolates from cattle. Vet Res Commun 1997, 21(6):409-420.

46. Cummings KJ, Warnick LD, Alexander KA, Cripps CJ, Grohn YT, James KL, McDonough PL, Reed KE: The duration of fecal Salmonella shedding following clinical disease among dairy cattle in the northeastern USA. Prev Vet Med 2009, 92:134-139.

47. Cobbold RN, Rice DH, Davis MA, Besser TE, Hancock DD: Long-term persistence of multi-drug-resistant Salmonella enterica serovar Newport in two dairy herds. J Am Vet Med Assoc 2006, 228(4):585-591.

48. Clegg FG, Chiejina SN, Duncan AL, Kay RN, Wray C: Outbreaks of Salmonella Newport infection in dairy herds and their relationship to management and contamination of the environment. Vet Rec 1983, 112(25):580-584

49. Fossler CP, Wells SJ, Kaneene JB, Ruegg PL, Warnick LD, Eberly LE, Godden SM, Halbert LW, Campbell AM, Bolin CA, Zwald AM: Cattle and environmental sample-level factors associated with the presence of Salmonella in a multi-state study of conventional and organic dairy farms. Prev Vet Med 2005, 67(1):39-53.

50. Murray CJ: Salmonellae in the environment. Rev Sci Tech 1991, 10(3):765-785

51. Blau DM, McCluskey BJ, Ladely SR, Dargatz DA, Fedorka-Cray PJ, Ferris KE, Headrick ML: Salmonella in dairy operations in the United States: prevalence and antimicrobial drug susceptibility. J Food Prot 2005, 68(4):696-702.

52. Callaway TR, Keen JE, Edrington TS, Baumgard LH, Spicer L, Fonda ES, Griswold KE, Overton TR, VanAmburgh ME, Anderson RC, Genovese KJ, Poole TL, Harvey RB, Nisbet DJ: Fecal prevalence and diversity of Salmonella species in lactating dairy cattle in four states. J Dairy Sci 2005, 88(10):3603-3608.

53. Ersboll AK, Nielsen LR: The range of influence between cattle herds is of importance for the local spread of Salmonella Dublin in Denmark. Prev Vet Med 2008, 84(3-4):277-290.

54. Huston CL, Wittum TE, Love BC, Keen JE: Prevalence of fecal shedding of Salmonella spp in dairy herds. J Am Vet Med Assoc 2002, 220(5):645-649.

55. Smith BP, Da Roden L, Thurmond MC, Dilling GW, Konrad H, Pelton JA, Picanso JP: Prevalence of salmonellae in cattle and in the environment on California dairies. J Am Vet Med Assoc 1994, 205(3):467-471.

56. Lailler R, Sanaa M, Chadoeuf J, Fontez B, Brisabois A, Colmin C, Millemann Y: Prevalence of multidrug resistant (MDR) Salmonella in bovine dairy herds in western France. Prev Vet Med 2005, 70(3-4):177-189.

57. Warnick LD, Crofton LM, Pelzer KD, Hawkins MJ: Risk factors for clinical salmonellosis in Virginia, USA cattle herds. Prev Vet Med 2001, 49(34):259-275.

58. Davies PR, Bovee FG, Funk JA, Morrow WE, Jones FT, Deen J: Isolation of Salmonella serotypes from feces of pigs raised in a multiple-site production system. J Am Vet Med Assoc 1998, 212(12):1925-1929.

59. Kasbohrer A, Protz D, Helmuth R, Nockler K, Blaha T, Conraths FJ, Geue L: Salmonella in slaughter pigs of German origin: an epidemiological study. Eur J Epidemiol 2000, 16(2):141-146.

60. Letellier A, Messier S, Pare J, Menard J, Quessy S: Distribution of Salmonella in swine herds in Quebec. Vet Microbiol 1999, 67(4):299-306.

61. Bahnson PB, Fedorka-Cray PJ, Ladely SR, Mateus-Pinilla NE: Herd-level risk factors for Salmonella enterica subsp. enterica in U.S. market pigs. Prev Vet Med 2006, 76(3-4):249-262.

62. Merialdi G, Barigazzi G, Bonilauri P, Tittarelli C, Bonci M, D'Incau M, Dottori M: Longitudinal study of Salmonella infection in Italian farrow-tofinish swine herds. Zoonoses Public Health 2008, 55(4):222-226.

63. Anonymous: [FIDIN antibiotic report 2006]. Tijdschr Diergeneeskd 2007, 132(13):538-539

64. Nollet N, Maes D, De Zutter L, Duchateau L, Houf K, Huysmans K, Imberechts H, Geers R, de Kruif A, Van Hoof J: Risk factors for the herdlevel bacteriologic prevalence of Salmonella in Belgian slaughter pigs. Prev Vet Med 2004, 65(1-2):63-75.

65. Nielsen LR, Schukken YH, Grohn YT, Ersboll AK: Salmonella Dublin infection in dairy cattle: risk factors for becoming a carrier. Prev Vet Med 2004, 65(1-2):47-62

66. Evans S, Davies R: Case control study of multiple-resistant Salmonella typhimurium DT104 infection of cattle in Great Britain. Vet Rec 1996, 139(23):557-558
67. Animal and Plant Health Inspection Service, United States Department of Agriculture: Report of the Committee on Salmonella, The National Veterinary Services Laboratory Report. 2006 [http://www.usaha.org/ committees/reports/2006/report-sal-2006.pdf].

68. USDA (United States Department of Agriculture), Center for Epidemiology and Animal Health (CEAH), National Animal Health Monitoring System (NAHMS): Dairy 2007: Salmonella and Campylobacter on U.S. Dairy Operations, 1996-2007. Fort Collins, CO: United States Department of Agriculture 2009 [http://www.aphis.usda.gov/animal_health/nahms/dairy/ index.shtml\#dairy2007].

69. USDA (United States Department of Agriculture), Center for Epidemiology and Animal Health (CEAH), National Animal Health Monitoring System (NAHMS): Beef 2007-08: Salmonella on U.S. Beef Cow-calf Operations, 2007-08. Fort Collins, CO: United States Department of Agriculture 2009 [http://www.aphis.usda.gov/animal_health/nahms/beefcowcalf/index. shtml\#beef0708].

70. USDA (United States Department of Agriculture), Center for Epidemiology and Animal Health (CEAH), National Animal Health Monitoring System (NAHMS): Feedlot 1999: Salmonella in United States Feedlots. Fort Collins, CO: United States Department of Agriculture 2001 [http://www.aphis.usda. gov/animal_health/nahms/feedlot/index.shtml].

71. Crump JA, Braden CR, Dey ME, Hoekstra RM, Rickelman-Apisa JM, Baldwin DA, De Fijter SJ, Nowicki SF, Koch EM, Bannerman TL, Smith FW, Sarisky JP, Hochberg N, Mead PS: Outbreaks of Escherichia coli 0157 infections at multiple county agricultural fairs: a hazard of mixing cattle, concession stands and children. Epidemiol Infect 2003, 131(3):1055-1062.

72. Hunter $A G$, Mathieson AO, Scott JA, Corrigall W: An outbreak of $S$. Typhimurium in sheep and its consequences. Vet Rec 1976, 98(7):126-130.

73. Fone DL, Barker RM: Associations between human and farm animal infections with Salmonella Typhimurium DT104 in Herefordshire. Commun Dis Rep CDR Rev 1994, 4(11):R136-140.

74. Sergevnin VI, Khasanov R, Parfenova KT, Vorob'eva W, Novgorodova SD: [An evaluation of the scope of the circulation of Salmonella among the workers of commercial poultry- and meat-packing enterprises based on serological study data in the PHA test]. Zh Mikrobiol Epidemiol Immunobiol 1992, 2: 51-54.

75. Molbak K, Baggesen DL, Aarestrup FM, Ebbesen JM, Engberg J, Frydendahl K, Gerner-Smidt P, Petersen AM, Wegener HC: An outbreak of multidrug-resistant, quinolone-resistant Salmonella enterica serotype Typhimurium DT104. N Engl J Med 1999, 341(19):1420-1425.

76. Kotova AL, Kondratskaya SA, Yasutis IM: Salmonella carrier state and biological characteristics of the infectious agent. J Hyg Epidemiol Microbiol Immunol 1988, 32(1):71-78.

77. Radke BR, McFall M, Radostits SM: Salmonella Muenster infection in a dairy herd. Can Vet J 2002, 43(6):443-453.

78. Uzzau S, Leori GS, Petruzzi V, Watson PR, Schianchi G, Bacciu D, Mazzarello V, Wallis TS, Rubino S: Salmonella enterica serovar-host specificity does not correlate with the magnitude of intestinal invasion in sheep. Infect Immun 2001, 69(5):3092-3099.

79. Sharma AK, Tripathi BN, Verma JC, Parihar NS: Experimental Salmonella enterica subspecies enterica serovar Typhimurium infection in Indian goats: clinical, serological, bacteriological and pathological studies. Small Ruminant Research 2001, 42(2):125-134.

80. Kusiluka L, Kambarag D: Diseases of small ruminants: a handbook. In Common Diseases of sheep and goats in Sub-Saharan Africa Edited by: VETAID: Overseas Development Administration Animal Health Program 1996.

81. Kumar S, Saxena SP, Gupta BK: Carrier rate of Salmonellas in sheep and goats and its public health significance. J Hyg (Lond) 1973, 71(1):43-47.

82. Habrun B, Listes E, Spicic S, Cvetnic Z, Lukacevic D, Jemersic L, Lojkic M, Kompes G: An outbreak of Salmonella Abortusovis abortions in sheep in south Croatia. J Vet Med B Infect Dis Vet Public Health 2006, 53(6):286-290.

83. Jack EJ: Salmonella abortion in sheep. Vet Annual 1971, 12:57-63.

84. Jack EJ: Salmonella Abortusovis: an atypical Salmonella. Vet Rec 1968, 82:558-561.

85. Murray JK, Browne WJ, Roberts MA, Whitmarsh A, Gruffydd-Jones TJ: Number and ownership profiles of cats and dogs in the UK. Vet Rec 166(6):163-168.

86. Uzzau S, Bossi L, Figueroa-Bossi N: Differential accumulation of Salmonella $[\mathrm{Cu}, \mathrm{Zn}]$ superoxide dismutases SodCl and SodCll in intracellular 
bacteria: correlation with their relative contribution to pathogenicity. Mol Microbiol 2002, 46(1):147-156.

87. Belloy L, Decrausaz L, Boujon P, Hachler H, Waldvogel AS: Diagnosis by culture and PCR of Salmonella Abortusovis infection under clinical conditions in aborting sheep in Switzerland. Vet Microbiol 2009, 138(34):373-377.

88. Alvseike O, Skjerve E: Prevalence of a Salmonella subspecies diarizonae in Norwegian sheep herds. Prev Vet Med 2002, 52(3-4):277-285.

89. Samuel JL, Eccles JA, Francis J: Salmonella in the intestinal tract and associated lymph nodes of sheep and cattle. J Hyg (Lond) 1981, 87(2):225-232.

90. Chandra M, Singh BR, Shankar H, Agarwal M, Agrawal RK, Sharma G, Babu N: Study on prevalence of Salmonella infection in goats. Small Rumin Res 2006, 65(1-2):24-30.

91. Chandra M, Singh BR, Shankar H, Agarwal M, Agarwal RK, Sharma G, Babu N: Prevalence of Salmonella antibodies among goats slaughtered for chevon in Bareilly (Northern India). Prev Vet Med 2007, 80(1):1-8.

92. Duffy L, Barlow R, Fegan N, Vanderlinde P: Prevalence and serotypes of Salmonella associated with goats at two Australian abattoirs. Lett Appl Microbiol 2009, 48(2):193-197.

93. Woldemariam E, Molla B, Alemayehu D, Muckle A: Prevalence and distribution of Salmonella in apparently healthy slaughtered sheep and goats in Debre Zeit, Ethiopia. Small Rumin Res 2005, 58(1):19-24.

94. Cortés C, de la Fuente R, Contreras A, Sánchez A, Corrales JC, Martínez S, José A, Orden JA: A survey of Salmonella spp. and Campylobacter spp. in dairy goat faeces and bulk tank milk in the Murcia region of Spain. lrish Vet J 2006, 59(7):391-393.

95. Hjartardottir S, Gunnarsson E, Sigvaldadottir J: Salmonella in sheep in Iceland. Acta Vet Scand 2002, 43(1):43-48.

96. Edrington TS, Long M, Ross TT, Thomas JD, Callaway TR, Anderson RC, Craddock F, Salisbury MW, Nisbet DJ: Prevalence and antimicrobial resistance profiles of Escherichia coli 0157:H7 and Salmonella isolated from feedlot lambs. J Food Prot 2009, 72(8):1713-1717.

97. Baker MG, Thornley CN, Lopez LD, Garrett NK, Nicol CM: A recurring salmonellosis epidemic in New Zealand linked to contact with sheep. Epidemiol Infect 2007, 135(1):76-83.

98. Cote S, Letellier A, Lessard L, Quessy S: Distribution of Salmonella in tissues following natural and experimental infection in pigs. Can I Vet Res 2004, 68(4):241-248.

99. Boyen F, Haesebrouck F, Maes D, Van Immerseel F, Ducatelle R, Pasmans F: Non-typhoidal Salmonella infections in pigs: A closer look at epidemiology, pathogenesis and control. Vet Microbiol 2008, 130(1-2):1-19.

100. Schofield FW: Salmonellosis in Swine: A Field and Laboratory Study of Four Outbreaks. Can J Comp Med Vet Sci 1944, 8(10):273-280.

101. Davies PR, Morrow WE, Jones FT, Deen J, Fedorka-Cray PJ, Harris IT: Prevalence of Salmonella in finishing swine raised in different production systems in North Carolina, USA. Epidemiol Infect 1997, 119(2):237-244.

102. Dahl J, Wingstrand A, Nielsen B, Baggesen DL: Elimination of Salmonella Typhimurium infection by the strategic movement of pigs. Vet Rec 1997, 140(26):679-681.

103. Hurd HS, McKean JD, Griffith RW, Wesley IV, Rostagno MH: Salmonella enterica infections in market swine with and without transport and holding. Appl Environ Microbiol 2002, 68(5):2376-2381.

104. Franklin A: "Be[a]ware of the Dog": A Post-Humanist Approach to Housing. Housing, Theory \& Society 2006, 23(3):137-156.

105. Society, Council for Society and Science: Companion animals in society. Oxford: Oxford University Press; 1988.

106. AVMA (American Veterinary Medical Association): U.S. Pet Ownership \& Demographics Sourcebook: American Veterinary Medical Association. 2007.

107. Katz J: The new work of dogs: tending to life, love, and family. New York: Villardi, 12003.

108. Laflamme DP, Abood SK, Fascetti AJ, Fleeman LM, Freeman LM, Michel KE, Bauer C, Kemp BL, Doren JR, Willoughby KN: Pet feeding practices of dog and cat owners in the United States and Australia. J Am Vet Med Assoc 2008, 232(5):687-694.

109. Mader B, Hart LA, Bergin B: Social acknowledegments for children with disabilities: effects of service dogs. Child Dev 1989, 60(6):1529-1534.

110. Draper RJ, Gerber GJ, Layng EM: Defining the role of pet animals in psychotherapy. Psychiatr J Univ Ott 1990, 15(3):169-172.
111. Brickel CM: A review of the roles of pet animals in psychotherapy and with the elderly. Int J Aging Hum Dev 1980, 12(2):119-128.

112. Carmack BJ: Companion animals: social support for orthopedic clients. Nurs Clin North Am 1998, 33(4):701-711.

113. Castelli P, Hart LA, Zasloff RL: Companion cats and the social support systems of men with AIDS. Psychol Rep 2001, 89(1):177-187.

114. Kongable LG, Buckwalter KC, Stolley JM: The effects of pet therapy on the social behavior of institutionalized Alzheimer's clients. Arch Psychiatr Nurs 1989, 3(4):191-198.

115. Lembo T, Hampson K, Kaare MT, Ernest E, Knobel D, Kazwala RR, Haydon DT, Cleaveland S: The feasibility of canine rabies elimination in Africa: dispelling doubts with data. PLoS Neg/ Trop Dis 4(2):e626.

116. Wenkoff MS: A review and case report. Salmonella Typhimurium septicemia in foals. Can Vet J 1973, 14(11):284-287.

117. Begg AP, Johnston KG, Hutchins DR, Edwards DJ: Some aspects of the epidemiology of equine salmonellosis. Aust Vet J 1988, 65(7):221-223.

118. Smith BP, Timm K, Jahn S, Reina-Guerra M: Salmonellosis in a group of ponies: failure to identify a chronic active carrier. J Am Vet Med Assoc 1980, 176(3):215-216

119. Roberts MC, O'Boyle DA: Experimental Salmonella Anatum infection in horses. Aust Vet J 1982, 58(6):232-240.

120. Morse EV, Duncan MA, Page EA, Fessler JF: Salmonellosis in Equidae: a study of 23 cases. Cornell Vet 1976, 66(2):198-213.

121. McCain CS, Powell KC: Asymptomatic salmonellosis in healthy adult horses. J Vet Diagn Invest 1990, 2(3):236-237.

122. Ikeda JS, Hirsh DC, Jang SS, Biberstein EL: Characteristics of Salmonella isolated from animals at a veterinary medical teaching hospital. Am J Vet Res 1986, 47(2):232-235.

123. Blikslager AT, Wilson DA, Taylor DS, MacFadden KE, Fischer JR, Fales WH: Salmonella Typhimurium abscess as a postoperative complication in a horse with colic. J Am Vet Med Assoc 1991, 199(12):1757-1759.

124. Platt H: Septicaemia in the foal. A review of 61 cases. Br Vet J 1973, 129(3):221-229.

125. Ernst NS, Hernandez JA, Mackay RJ, Brown MP, Gaskin JM, Nguyen AD, Giguere S, Colahan PT, Troedsson MR, Haines GR, Addison IR, Miller BJ: Risk factors associated with fecal Salmonella shedding among hospitalized horses with signs of gastrointestinal tract disease. J Am Vet Med Assoc 2004, 225(2):275-281

126. Stuart BP, Martin BR, Williams LP Jr, Von Byern H: Salmonella-induced meningoencephalitis in a foal. J Am Vet Med Assoc 1973, 162(3):211-213.

127. Donahue JM: Emergence of antibiotic-resistant Salmonella Agona in horses in Kentucky. J Am Vet Med Assoc 1986, 188(6):592-594.

128. Madic J, Hajsig D, Sostaric B, Curic S, Seol B, Naglic T, Cvetnic Z: An outbreak of abortion in mares associated with Salmonella Abortusequi infection. Equine Vet J 1997, 29(3):230-233

129. Kumar S, Gupta BK: Salmonella Anatum from an aborted foal. Br Vet J 1972, 128(11):|xiv.

130. Anderson GD, Lee DR: Salmonella in horses: a source of contamination of horsemeat in a packing plant under federal inspection. Appl Environ Microbiol 1976, 31(5):661-663.

131. Traub-Dargatz JL, Garber LP, Fedorka-Cray PJ, Ladely S, Ferris KE: Fecal shedding of Salmonella spp by horses in the United States during 1998 and 1999 and detection of Salmonella spp in grain and concentrate sources on equine operations. J Am Vet Med Assoc 2000, 217(2):226-230.

132. Ewart SL, Schott HC, Robison RL, Dwyer RM, Eberhart SW, Walker RD: Identification of sources of Salmonella organisms in a veterinary teaching hospital and evaluation of the effects of disinfectants on detection of Salmonella organisms on surface materials. J Am Vet Med Assoc 2001, 218(7):1145-1151.

133. Kim LM, Morley PS, Traub-Dargatz IL, Salman MD, Gentry-Weeks C: Factors associated with Salmonella shedding among equine colic patients at a veterinary teaching hospital. J Am Vet Med Assoc 2001, 218(5):740-748.

134. Ravary B, Fecteau G, Higgins R, Pare J, Lavoie JP: Prevalence of infections caused by Salmonella spp. in cattle and horses at the Veterinary Teaching Hospital of the Faculty of Veterinary Medicine of the University of Montreal. Can Vet J 1998, 39(9):566-572, (article in French).

135. Roberts MC, O'Boyle DA: The prevalence and epizootiology of salmonellosis among groups of horses in south east Queensland. Aust Vet J 1981, 57(1):27-35. 
136. Hirsh DC, Smith BP: Pleasure horses as a possible source of Salmonella Agona. Am J Vet Res 1979, 40(9):1301-1302.

137. Hird DW, Pappaioanou M, Smith BP: Case-control study of risk factors associated with isolation of Salmonella Saintpaul in hospitalized horses. Am J Epidemiol 1984, 120(6):852-864.

138. Traub-Dargatz JL, Salman MD, Jones RL: Epidemiologic study of salmonellae shedding in the feces of horses and potential risk factors for development of the infection in hospitalized horses. J Am Vet Med Assoc 1990, 196(10):1617-1622.

139. House JK, Mainar-Jaime RC, Smith BP, House AM, Kamiya DY: Risk factors for nosocomial Salmonella infection among hospitalized horses. J Am Vet Med Assoc 1999, 214(10):1511-1516.

140. Owen RA, Fullerton J, Barnum DA: Effects of transportation, surgery, and antibiotic therapy in ponies infected with Salmonella. Am J Vet Res 1983, 44(1):46-50,

141. Hartmann FA, Callan RJ, McGuirk SM, West SE: Control of an outbreak of salmonellosis caused by drug-resistant Salmonella Anatum in horses at a veterinary hospital and measures to prevent future infections. J Am Vet Med Assoc 1996, 209(3):629-631.

142. Morse EV, Duncan MA: Salmonellosis-an environmental health problem. J Am Vet Med Assoc 1974, 165(11):1015-1019.

143. Tillotson K, Savage CJ, Salman MD, Gentry-Weeks CR, Rice D, FedorkaCray PJ, Hendrickson DA, Jones RL, Nelson W, Traub-Dargatz JL: Outbreak of Salmonella Infantis infection in a large animal veterinary teaching hospital. J Am Vet Med Assoc 1997, 211(12):1554-1557.

144. Weese JS: A Review of Equine Zoonotic Diseases: Risks in Veterinary Medicine. Proceedings of the Annual Convention of the AAEP 2002, 48.

145. Bender JB, Tsukayama DT: Horses and the risk of zoonotic infections. Vet Clin North Am Equine Pract 2004, 20(3):643-653.

146. Allison CJ: The dog as a symptomless carrier of Salmonella Typhimurium. Vet Rec 1969, 85(20):564.

147. Shimi A, Barin A: Salmonella in cats. J Comp Pathol 1977, 87(2):315-318.

148. Morse EV, Duncan MA, Estep DA, Riggs WA, Blackburn BO: Canine salmonellosis: A review and report of dog to child transmission of Salmonella Enteritidis. Am J Public Health 1976, 66(1):82-84.

149. Philbey AW, Brown FM, Mather HA, Coia JE, Taylor DJ: Salmonellosis in cats in the United Kingdom: 1955 to 2007. Vet Rec 2009, 164(4):120-122.

150. Caldow GL, Graham MM: Abortion in foxhounds and a ewe flock associated with Salmonella Montevideo infection. Vet Rec 1998, 142(6):138-139.

151. Carter ME, Quinn PJ: Salmonella Infections in Dogs and Cats. In Salmonella in Domestic Animals. Edited by: Wray CaW, A. London: CABI Publishing International; 2000:

152. Bagcigil AF, Ikiz S, Dokuzeylu B, Basaran B, Or E, Ozgur NY: Fecal shedding of Salmonella spp. in dogs. J Vet Med Sci 2007, 69(7):775-777.

153. Cantor GH, Nelson S Jr, Vanek JA, Evermann JF, Eriks IS, Basaraba RJ, Besser TE: Salmonella shedding in racing sled dogs. J Vet Diagn Invest 1997, 9(4):447-448.

154. Stucker CL, Galton MM, Cowdery J, Hardy AV: Salmonellosis in dogs. II. Prevalence and distribution in greyhounds in Florida. J Infect Dis 1952, 91(1):6-11.

155. Gorham JR, Garner FM: The incidence of Salmonella infections in dogs and cats in a nonu ban area. Am J Vet Res 1951, 12(42):35-37.

156. Kwaga JK, Adesiyun AA, Abdullahi SU, Bello CS: Prevalence of salmonellae, shigellae and Plesiomonas shigelloides in dogs in Zaria, Nigeria. Br Vet $J$ 1989, 145(2):174-177.

157. Weber A, Wachowitz R, Weigl U, Schafer-Schmidt R: Occurrence of Salmonella in fecal samples of dogs and cats in northern Bavaria from 1975 to 1994. Berl Munch Tierarztl Wochenschr 1995, 108(11):401-404, (article in German).

158. Hackett T, Lappin MR: Prevalence of enteric pathogens in dogs of northcentral Colorado. J Am Anim Hosp Assoc 2003, 39(1):52-56.

159. Hill SL, Cheney JM, Taton-Allen GF, Reif JS, Bruns C, Lappin MR: Prevalence of enteric zoonotic organisms in cats. J Am Vet Med Assoc 2000, 216(5):687-692.

160. Spain CV, Scarlett JM, Wade SE, McDonough P: Prevalence of enteric zoonotic agents in cats less than 1 year old in central New York State. $J$ Vet Intern Med 2001, 15(1):33-38.

161. Tanaka Y, Katsube Y, Imaizumi K: Experimental carrier in dogs produced by oral administration of Salmonella Typhimurium. Nippon Juigaku Zasshi 1976, 38(6):569-578.
162. Chengappa MM, Staats J, Oberst RD, Gabbert NH, McVey S: Prevalence of Salmonella in raw meat used in diets of racing greyhounds. J Vet Diagn Invest 1993, 5(3):372-377.

163. Finley R, Ribble C, Aramini J, Vandermeer M, Popa M, Litman M, ReidSmith $R$ : The risk of salmonellae shedding by dogs fed Salmonellacontaminated commercial raw food diets. Can Vet J 2007, 48(1):69-75.

164. Joffe DJ, Schlesinger DP: Preliminary assessment of the risk of Salmonella infection in dogs fed raw chicken diets. Can Vet J 2002, 43(6):441-442

165. Lefebvre SL, Reid-Smith R, Boerlin P, Weese JS: Evaluation of the risks of shedding Salmonellae and other potential pathogens by therapy dogs fed raw diets in Ontario and Alberta. Zoonoses Public Health 2008, 55(810):470-480.

166. Mackel DC, Galton MM, Gray H, Hardy AV: Salmonellosis in dogs. IV. Prevalence in normal dogs and their contacts. J Infect Dis 1952, 91(1):15-18

167. Guardabassi L, Schwarz S, Lloyd DH: Pet animals as reservoirs of antimicrobial-resistant bacteria: Review. J Antimicrob Chemother 2004, 54(2):321-332.

168. Younus M, Wilkins M, Davies H, Rahbar M, Funk J, Nguyen C, Siddiqi AE, Cho S, Saeed M: Case-control study of disease determinants for nontyphoidal Salmonella infections among Michigan children. BMC Res Notes 2010, 3(1):105.

169. Schotte U, Borchers D, Wulff C, Geue L: Salmonella Montevideo outbreak in military kennel dogs caused by contaminated commercial feed, which was only recognized through monitoring. Vet Microbiol 2007, 119(2-4):316-323.

170. Finley R, Reid-Smith R, Ribble C, Popa M, Vandermeer M, Aramini J: The occurrence and antimicrobial susceptibility of salmonellae isolated from commercially available canine raw food diets in three Canadian cities. Zoonoses Public Health 2008, 55(8-10):462-469.

171. CDC (Centers for Disease Control and Prevention): Multistate outbreak of human Salmonella infections caused by contaminated dry dog foodUnited States, 2006-2007. MMWR Morb Mortal Wkly Rep 2008, 57(19):521-524.

172. White DG, Datta A, McDermott P, Friedman S, Qaiyumi S, Ayers S, English L, McDermott S, Wagner DD, Zhao S: Antimicrobial susceptibility and genetic relatedness of Salmonella serovars isolated from animal-derived dog treats in the USA. J Antimicrob Chemother 2003, 52(5):860-863.

173. Clark C, Cunningham J, Ahmed R, Woodward D, Fonseca K, Isaacs S, Ellis A, Anand C, Ziebell K, Muckle A, Sockett P, Rodgers F: Characterization of Salmonella associated with pig ear dog treats in Canada. J Clin Microbiol 2001, 39(11):3962-3968.

174. Finley R, Reid-Smith R, Ribble C, Popa M, Vandermeer M, Aramini J: The occurrence and anti-microbial susceptibility of Salmonellae isolated from commercially available pig ear pet treats. Zoonoses Public Health 2008, 55(8-10):455-461.

175. Healing TD: Salmonella in rodents: a risk to man? CDR (Lond Engl Rev) 1991, 1(10):R114-116

176. Meerburg BG, Jacobs-Reitsma WF, Wagenaar JA, Kijlstra A: Presence of Salmonella and Campylobacter spp. in wild small mammals on organic farms. Appl Environ Microbiol 2006, 72(1):960-962.

177. Singh SP, Sethi MS, Sharma VD: The occurrence of salmonellae in rodent, shrew, cockroach and ant. Int J Zoonoses 1980, 7(1):58-61.

178. Shimi A, Keyhani M, Hedayati K: Studies on salmonellosis in the house mouse, Mus musculus. Lab Anim 1979, 13(1):33-34.

179. Yokoyama E, Maruyama S, Kabeya H, Hara S, Sata S, Kuroki T, Yamamoto T: Prevalence and genetic properties of Salmonella enterica serovar Typhimurium definitive phage type 104 isolated from Rattus norvegicus and Rattus rattus house rats in Yokohama City, Japan. Appl Environ Microbiol 2007, 73(8):2624-2630.

180. Lee KM, McReynolds JL, Fuller CC, Jones B, Herrman TJ, Byrd JA, Runyon M: Investigation and characterization of the frozen feeder rodent industry in Texas following a multi-state Salmonella Typhimurium outbreak associated with frozen vacuum-packed rodents. Zoonoses Public Health 2008, 55(8-10):488-496.

181. Zahraei T, Mahzouniehand M, Khaksar E: Detection of Salmonella serovars in zoo and pet reptiles, rabbits, and rodents in Iran by culture and PCR methods. Comp Clin Pathol 2010, 19:199-202.

182. Agnoletti F, Lenarduzzi M, Ricci A, Marotta A: Isolation of Salmonella spp, from Italian commercial rabbitries. CIHEAM - Options Méditerranéennes 1999 
183. Rodriguez-Calleja JM, Garcia-Lopez I, Garcia-Lopez ML, Santos JA, Otero A: Rabbit meat as a source of bacterial foodborne pathogens. J Food Prot 2006, 69(5):1106-1112.

184. Painter JA, Molbak K, Sonne-Hansen J, Barrett T, Wells JG, Tauxe RV: Salmonella-based rodenticides and public health. Emerg Infect Dis 2004, 10(6):985-987

185. Friedman CR, Malcolm G, Rigau-Perez JG, Arambulo P, Tauxe RV: Public health risk from Salmonella-based rodenticides. Lancet 1996, 347(9016):1705-1706.

186. Kirchner BK, Dixon LW, Lentsch RH, Wagner JE: Recovery and pathogenicity of several Salmonella species isolated from mice. Lab Anim Sci 1982, 32(5):506-508

187. Simmons DJ, Simpson W: Salmonella Montevideo salmonellosis in laboratory mice: successful treatment of the disease by oral oxytetracycline. Lab Anim 1980, 14(3):217-219

188. lijima OT, Saito M, Nakayama K, Kobayashi S, Matsuno K, Nakagawa M: Epizootiological studies of Salmonella Typhimurium infection in guinea pigs. Jikken Dobutsu 1987, 36(1):39-49.

189. Olfert ED, Ward GE, Stevenson D: Salmonella Typhimurium infection in guinea pigs: observations on monitoring and control. Lab Anim Sci 1976, 26(1):78-80.

190. Reaser JK, Clark EE Jr, Meyers NM: All creatures great and minute: a public policy primer for companion animal zoonoses. Zoonoses Public Health 2008, 55(8-10):385-401.

191. Pickering LK, Marano N, Bocchini JA, Angulo FJ: Exposure to nontraditional pets at home and to animals in public settings: risks to children. Pediatrics 2008, 122(4):876-886.

192. Handeland K, Refsum T, Johansen BS, Holstad G, Knutsen G, Solberg I, Schulze J, Kapperud G: Prevalence of Salmonella Typhimurium infection in Norwegian hedgehog populations associated with two human disease outbreaks. Epidemiol Infect 2002, 128(3):523-527.

193. Nauerby B, Pedersen K, Dietz HH, Madsen M: Comparison of Danish isolates of Salmonella enterica serovar enteritidis PT9a and PT11 from hedgehogs (Erinaceus europaeus) and humans by plasmid profiling and pulsed-field gel electrophoresis. J Clin Microbio/ 2000, 38(10):3631-3635.

194. Booth RJ: Sugar Gliders. In The Merk Veterinary Manual.. 9 edition. Edited by: Kahn CM. Whitehouse Station, NJ, USA: Merck 2008:

195. Riley PY, Chomel BB: Hedgehog zoonoses. Emerg Infect Dis 2005, 11(1):1-5.

196. Woodward DL, Khakhria R, Johnson WM: Human salmonellosis associated with exotic pets. J Clin Microbiol 1997, 35(11):2786-2790.

197. Lutful Kabir SM: Avian colibacillosis and salmonellosis: a closer look at epidemiology, pathogenesis, diagnosis, control and public health concerns. Int J Environ Res Public Health 7(1):89-114.

198. Padron M: Salmonella Typhimurium outbreak in broiler chicken flocks in Mexico. Avian Dis 1990, 34(1):221-223.

199. Borland ED: Salmonella infection in poultry. Vet Rec 1975, 97(21):406-408.

200. Shivaprasad HL: Fowl typhoid and pullorum disease. Rev Sci Tech 2000 , 19(2):405-424.

201. Anderson LA, Miller DA, Trampel DW: Epidemiological investigation, cleanup, and eradication of pullorum disease in adult chickens and ducks in two small-farm flocks. Avian Dis 2006, 50(1):142-147.

202. Guard-Petter J: The chicken, the egg and Salmonella Enteritidis. Environ Microbiol 2001, 3(7):421-430.

203. Roberts JA, Sockett PN: The socio-economic impact of human Salmonella Enteritidis infection. Int J Food Microbiol 1994, 21(1-2):117-129.

204. Bailey JS, Cox NA, Berrang ME: Hatchery-acquired salmonellae in broiler chicks. Poult Sci 1994, 73(7):1153-1157.

205. Chao MR, Hsien CH, Yeh CM, Chou SJ, Chu C, Su YC, Yu CY: Assessing the prevalence of Salmonella enterica in poultry hatcheries by using hatched eggshell membranes. Poult Sci 2007, 86(8):1651-1655.

206. Foley SL, Lynne AM, Nayak R: Salmonella challenges: prevalence in swine and poultry and potential pathogenicity of such isolates. J Anim Sci 2008, 86(14 Suppl):E149-162

207. Rabsch W, Hargis BM, Tsolis RM, Kingsley RA, Hinz KH, Tschape H, Baumler AJ: Competitive exclusion of Salmonella Enteritidis by Salmonella Gallinarum in poultry. Emerg Infect Dis 2000, 6(5):443-448.

208. CDC (Centers for Disease Control and Prevention): Salmonellosis associated with chicks and ducklings-Michigan and Missouri, Spring 1999. MMWR Morb Mortal Wkly Rep 2000, 49(14):297-299.
209. CDC (Centers for Disease Control and Prevention): Multistate outbreaks of Salmonella infections associated with live poultry-United States, 2007. MMWR Morb Mortal Wkly Rep 2009, 58(2):25-29.

210. Anderson A, Bauer $H$, Nelson CB: Salmonellosis due to Salmonella Typhimurium with Easter chicks as likely source. J Am Med Assoc 1955, 158:1153-1155

211. McCroan JE, McKinley TW, Brim A, Ramsey CH: Five Salmonellosis Outbreaks Related to Poultry Products. Public Health Rep 1963 78:1073-1080.

212. CDC (Centers for Disease Control and Prevention): Three outbreaks of salmonellosis associated with baby poultry from three hatcheriesUnited States, 2006. MMWR Morb Mortal Wkly Rep 2007, 56(12):273-276

213. CDC (Centers for Disease Control and Prevention): Salmonella serotype Montevideo infections associated with chicks-Idaho, Washington, and Oregon, spring 1995 and 1996. MMWR Morb Mortal Wkly Rep 1997, 46(11):237-239.

214. CDC (Centers for Disease Control and Prevention): Healthy pets healthy people.[http://www.cdc.gov/healthypets/].

215. Henry RR: Salmonella infection in ducks. In Salmonella in Domestic Animals. Edited by: Wray CaW, A. London: CABI Publishing; 2000:157-169.

216. Yu CY, Chu C, Chou SJ, Chao MR, Yeh CM, Lo DY, Su YC, Horng YM, Weng BC, Tsay JG, Huang KC: Comparison of the association of age with the infection of Salmonella and Salmonella enterica Serovar Typhimurium in Pekin ducks and Roman geese. Poult Sci 2008, 87(8):1544-1549.

217. Tizard I: Salmonellosis in wild birds. Sem Avian Exotic Pet Med 2004 13(2):50-66.

218. Mitchell TR, Ridgwell T: The frequency of salmonellae in wild ducks. J Med Microbiol 1971, 4(3):359-361.

219. Palmgren $H$, Aspan A, Broman T, Bengtsson $K$, Blomquist $L$, Bergstrom $S$ Sellin M, Wollin R, Olsen B: Salmonella in Black-headed gulls (Larus ridibundus); prevalence, genotypes and influence on Salmonella epidemiology. Epidemiol Infect 2006, 134(3):635-644.

220. Girdwood RW, Fricker CR, Munro D, Shedden CB, Monaghan P: The incidence and significance of Salmonella carriage by gulls (Larus spp.) in Scotland. J Hyg (Lond) 1985, 95(2):229-241

221. Ma D, Wang R, Liao W, Han Z, Liu S: Identification and characterization of a novel antibacterial peptide, avian beta-defensin 2 from ducks. J Microbiol 2009, 47(5):610-618.

222. Faddoul GP, Fellows GW: Clinical Manifestations of Paratyphoid Infection in Pigeons. Avian Dis 1965, 22:377-381.

223. Pasmans F, Van Immerseel F, Heyndrickx M, Martel A, Godard C, Wildemauwe C, Ducatelle R, Haesebrouck F: Host adaptation of pigeon isolates of Salmonella enterica subsp. enterica serovar Typhimurium variant Copenhagen phage type 99 is associated with enhanced macrophage cytotoxicity. Infect Immun 2003, 71(10):6068-6074.

224. Pedersen K, Clark L, Andelt WF, Salman MD: Prevalence of shiga toxinproducing Escherichia coli and Salmonella enterica in rock pigeons captured in Fort Collins, Colorado. J Wildl Dis 2006, 42(1):46-55.

225. Tanaka C, Miyazawa T, Watarai M, Ishiguro N: Bacteriological survey of feces from feral pigeons in Japan. J Vet Med Sci 2005, 67(9):951-953.

226. Oros J, Rodriguez JL, Fernandez A, Herraez P, Espinosa de los Monteros A Jacobson ER: Simultaneous occurrence of Salmonella arizonae in a sulfur crested cockatoo (Cacatua galerita galerita) and iguanas. Avian Dis 1998 42(4):818-823.

227. Panigrahy B, Grimes JE, Rideout MI, Simpson RB, Grumbles LC: Zoonotic diseases in psittacine birds: apparent increased occurrence of chlamydiosis (psittacosis), salmonellosis, and giardiasis. J Am Vet Med Assoc 1979, 175(4):359-361.

228. Panigrahy B, Gilmore WC: Systemic salmonellosis in an African gray parrot and Salmonella osteomyelitis in canaries. J Am Vet Med Assoc 1983, 183(6):699-700.

229. Ward MP, Ramer JC, Proudfoot J, Garner MM, Juan-Salles C, Wu CC: Outbreak of salmonellosis in a zoologic collection of lorikeets and lories (Trichoglossus, Lorius, and Eos spp.). Avian Dis 2003, 47(2):493-498.

230. Wernery $U$, Wernery $R$, Zachariah $R$, Kinne J: Salmonellosis in relation to chlamydiosis and pox and Salmonella infections in captive falcons in the United Arab Emirates. Zentralb/ Veterinarmed B 1998, 45(10):577-583.

231. Locke LN, Ohlendorf HM, Shillinger RB, Jareed T: Salmonellosis in a captive heron colony. J Wildl Dis 1974, 10(2):143-145. 
232. Madewell BR, McChesney AE: Salmonellosis in a human infant, a cat, and two parakeets in the same household. J Am Vet Med Assoc 1975, 167(12):1089-1090

233. Harris IT, Fedorka-Cray PJ, Gray JT, Thomas LA, Ferris K: Prevalence of Salmonella organisms in swine feed. J Am Vet Med Assoc 1997, 210(3):382-385.

234. Barber DA, Bahnson PB, Isaacson R, Jones CJ, Weigel RM: Distribution of Salmonella in swine production ecosystems. J Food Prot 2002, 65(12):1861-1868.

235. Zheng DM, Bonde M, Sørensen JT: Associations between the proportion of Salmonella seropositive slaughter pigs and the presence of herd level risk factors for introduction and transmission of Salmonella in 34 Danish organic, outdoor (non-organic) and indoor finishing-pig farms. Livestock Science 2007, 106(2-3):189-199.

236. Davies $\mathrm{RH}$, Wray C: Distribution of Salmonella contamination in ten animal feedmills. Vet Microbiol 1997, 57(2-3):159-169.

237. Hudson CR, Quist C, Lee MD, Keyes K, Dodson SV, Morales C, Sanchez S, White DG, Maurer JJ: Genetic relatedness of Salmonella isolates from nondomestic birds in Southeastern United States. J Clin Microbio/ 2000, 38(5):1860-1865

238. Brittingham MC, Temple SA, Duncan RM: A survey of the prevalence of selected bacteria in wild birds. J Wildl Dis 1988, 24(2):299-307.

239. Alley MR, Connolly JH, Fenwick SG, Mackereth GF, Leyland MJ, Rogers LE, Haycock M, Nicol C, Reed CE: An epidemic of salmonellosis caused by Salmonella Typhimurium DT160 in wild birds and humans in New Zealand. N Z Vet J 2002, 50(5):170-176.

240. Thornley CN, Simmons GC, Callaghan ML, Nicol CM, Baker MG, Gilmore KS, Garrett NK: First incursion of Salmonella enterica serotype typhimurium DT160 into New Zealand. Emerg Infect Dis 2003, 9(4):493-495.

241. Kapperud G, Stenwig H, Lassen J: Epidemiology of Salmonella Typhimurium 0:4-12 infection in Norway: evidence of transmission from an avian wildlife reservoir. Am J Epidemio/ 1998, 147(8):774-782.

242. Smith KE, Anderson F, Medus C, Leano F, Adams J: Outbreaks of salmonellosis at elementary schools associated with dissection of owl pellets. Vector Borne Zoonotic Dis 2005, 5(2):133-136.

243. Bemis DA, Grupka LM, Liamthong S, Folland DW, Sykes JMt, Ramsay EC: Clonal relatedness of Salmonella isolates associated with invasive infections in captive and wild-caught rattlesnakes. Vet Microbio/ 2007, 120(3-4):300-307.

244. Ramsay EC, Daniel GB, Tryon BW, Merryman Jl, Morris PJ, Bemis DA: Osteomyelitis associated with Salmonella enterica SS arizonae in a colony of ridgenose rattlesnakes (Crotalus willardi). J Zoo Wildl Med 2002, 33(4):301-310.

245. Glazebrook S, Campbell RS: A survey of the diseases of marine turtles in northern Australia. I. Farmed turtles. Dis Aquat Org 1990, 9:83-95.

246. Chiodini RJ, Sundberg JP: Salmonellosis in reptiles: a review. Am J Epidemiol 1981, 113(5):494-499.

247. Pasmans F, De Herdt P, Dewulf J, Haesebrouck F: Pathogenesis of infections with Salmonella enterica subsp. enterica serovar Muenchen in the turtle Trachemys scripta scripta. Vet Microbiol 2002, 87(4):315-325.

248. Mitchell MA, Diaz-Figueroa O: Clinical reptile gastroenterology. Vet Clin North Am Exot Anim Pract 2005, 8(2):277-298.

249. Gartrell BD, Youl JM, King CM, Bolotovski I, McDonald WL, Nelson NJ: Failure to detect Salmonella species in a population of wild tuatara (Sphenodon punctatus). N Z Vet J 2007, 55(3):134-136.

250. Richards JM, Brown JD, Kelly TR, Fountain AL, Sleeman JM: Absence of detectable Salmonella cloacal shedding in free-living reptiles on admission to the wildlife center of Virginia. J Zoo Wildl Med 2004, 35:562-563.

251. Oboegbulem SI, Iseghohimhen AU: Wall Geckos (Geckonidae) as reservoirs of Salmonellae in Nigeria: problems for epidemiology and public health. Int J Zoonoses 1985, 12(3):228-232.

252. Briones V, Tellez S, Goyache J, Ballesteros C, del Pilar Lanzarot M, Dominguez L, Fernandez-Garayzabal JF: Salmonella diversity associated with wild reptiles and amphibians in Spain. Environ Microbiol 2004, 6(8):868-871.

253. Chambers DL, Hulse AC: Salmonella serovars in the herpetofauna of Indiana County, Pennsylvania. Appl Environ Microbiol 2006, 72(5):3771-3773

254. Gaertner JP, Hahn D, Rose FL, Forstner MR: Detection of salmonellae in different turtle species within a headwater spring ecosystem. J Wildl Dis 2008, 44(2):519-526.
255. Hidalgo-Vila J, Diaz-Paniagua C, Perez-Santigosa N, de Frutos-Escobar C, Herrero-Herrero A: Salmonella in free-living exotic and native turtles and in pet exotic turtles from SW Spain. Res Vet Sci 2008, 85(3):449-452.

256. Pasmans F, Martel A, Boyen F, Vandekerchove D, Wybo I, Immerseel FV, Heyndrickx M, Collard JM, Ducatelle R, Haesebrouck F: Characterization of Salmonella isolates from captive lizards. Vet Microbiol 2005, 110(34):285-291.

257. Nakadai A, Kuroki T, Kato Y, Suzuki R, Yamai S, Yaginuma C, Shiotani R, Yamanouchi A, Hayashidani H: Prevalence of Salmonella spp. in pet reptiles in Japan. J Vet Med Sci 2005, 67(1):97-101.

258. Siebeling RJ, Neal PM, Granberry WD: Treatment of Salmonella-Arizonainfected turtle eggs with terramycin and chloromycetin by the temperature-differential egg dip method. Appl Microbio/ 1975, 30(5):791-799

259. Michael-Marler S, Brown ML, Siebeling RJ: Eradication of Arizona hinshawii from artificially infected turtle eggs. Appl Environ Microbiol 1983, 45(3):748-754.

260. Siebeling RJ, Caruso D, Neuman S: Eradication of Salmonella and Arizona species from turtle hatchlings produced from eggs treated on commercial turtle farms. Appl Environ Microbiol 1984, 47(4):658-662.

261. Mitchell MA, Adamson TW, Singleton CB, Roundtree MK, Bauer RW, Acierno MJ: Evaluation of a combination of sodium hypochlorite and polyhexamethylene biguanide as an egg wash for red-eared slider turtles (Trachemys scripta elegans) to suppress or eliminate Salmonella organisms on egg surfaces and in hatchlings. Am J Vet Res 2007, 68(2):158-164.

262. D'Aoust JY, Daley E, Crozier M, Sewell AM: Pet turtles: a continuing international threat to public health. Am J Epidemiol 1990, 132(2):233-238.

263. Ducluzeau R: Influence of the zoological species on the microflora of the gastrointestinal tract. Rev Immunol Ther Antimicrob 1969, 33(6):345-383, (article in French).

264. Chiodini RJ: Transovarian passage, visceral distribution, and pathogenicity of Salmonella in snakes. Infect Immun 1982, 36(2):710-713.

265. Mermin J, Hutwagner L, Vugia D, Shallow S, Daily P, Bender J, Koehler J, Marcus R, Angulo FJ: Reptiles, amphibians, and human Salmonella infection: a population-based, case-control study. Clin Infect Dis 2004, 38(Suppl 3):S253-261.

266. Bertrand S, Rimhanen-Finne R, Weill FX, Rabsch W, Thornton L, Perevoscikovs J, van Pelt W, Heck M: Salmonella infections associated with reptiles: the current situation in Europe. Euro Surveill 2008, 13(24):18902.

267. de Jong $B$, Andersson $Y$, Ekdahl K: Effect of regulation and education on reptile-associated salmonellosis. Emerg Infect Dis 2005, 11(3):398-403.

268. Olsen SJ, Bishop R, Brenner FW, Roels TH, Bean N, Tauxe RV, Slutsker L: The changing epidemiology of Salmonella: trends in serotypes isolated from humans in the United States, 1987-1997. J Infect Dis 2001, 183(5):753-761.

269. CDC (Centers for Disease Control and Prevention): Multistate outbreak of human Salmonella infections associated with exposure to turtles-United States, 2007-2008. MMWR Morb Mortal Wkly Rep 2008, 57(3):69-72.

270. Friedman CR, Torigian C, Shillam PJ, Hoffman RE, Heltzel D, Beebe JL, Malcolm G, DeWitt WE, Hutwagner L, Griffin PM: An outbreak of salmonellosis among children attending a reptile exhibit at a zoo. J Pediatr 1998, 132(5):802-807.

271. CDC (Centers for Disease Control and Prevention): Reptile-associated salmonellosis-selected states, 1994-1995. MMWR Morb Mortal Wkly Rep 1995, 44(17):347-350

272. Mermin J, Hoar B, Angulo FJ: Iguanas and Salmonella marina infection in children: a reflection of the increasing incidence of reptile-associated salmonellosis in the United States. Pediatrics 1997, 99(3):399-402.

273. CDC (Centers for Disease Control and Prevention): Reptile-associated salmonellosis-selected states, 1998-2002. MMWR Morb Mortal Wkly Rep 2003, 52(49):1206-1209.

274. CDC (Centers for Disease Control and Prevention): Salmonellosis associated with pet turtles-Wisconsin and Wyoming, 2004. MMWR Morb Mortal Wkly Rep 2005, 54(9):223-226.

275. Scott T, Foster BG: Salmonella spp. in free-ranging and farmed alligators (Alligator mississippiensis) from Texas and Louisiana U.S.A. Aquaculture 1997, 156(1-2):179-181

276. Madsen $M$, Hangartner $P$, West $K$, Kelly P: Recovery rates, serotypes, and antimicrobial susceptibility patterns of salmonellae isolated from cloacal swabs of wild Nile crocodiles (Crocodylus niloticus) in Zimbabwe. J Zoo Wild Med 1998, 29(1):31-34. 
277. Gugnani HC, Oguike JU, Sakazaki R: Salmonellae and other enteropathogenic bacteria in the intestines of wall geckos in Nigeria. Antonie Van Leeuwenhoek 1986, 52(2):117-120.

278. Kourany M, Telford SR: Lizards in the ecology of salmonellosis in Panama. Appl Environ Microbiol 1981, 41(5):1248-1253.

279. van der Walt ML, Huchzermeyer FW, Steyn HC: Salmonella isolated from crocodiles and other reptiles during the period 1985-1994 in South Africa. Onderstepoort J Vet Res 1997, 64(4):277-283.

280. Lamm SH, Taylor A Jr, Gangarosa EJ, Anderson HW, Young W, Clark MH, Bruce AR: Turtle-associated salmonellosis. I. An estimation of the magnitude of the problem in the United States, 1970-1971. Am J Epidemiol 1972, 95(6):511-517.

281. Cohen ML, Potter M, Pollard R, Feldman RA: Turtle-associated salmonellosis in the United States. Effect of Public Health Action, 1970 to 1976. JAMA 1980, 243(12):1247-1249.

282. CDC (Centers for Disease Control and Prevention): Turtle-associated salmonellosis in humans-United States, 2006-2007. MMWR Morb Mortal Wkly Rep 2007, 56(26):649-652.

283. Everard CO, Tota B, Bassett D, Ali C: Salmonella in wildlife from Trinidad and Grenada, W.I. J Wildl Dis 1979, 15(2):213-219.

284. Geue L, Loschner U: Salmonella enterica in reptiles of German and Austrian origin. Vet Microbiol 2002, 84(1-2):79-91.

285. CDC (Centers for Disease Control and Prevention): Multistate outbreak of human Salmonella Typhimurium infections associated with aquatic frogs - United States, 2009. MMWR Morb Mortal Wkly Rep 2009, 58(51):1433-1436.

286. Srikantiah P, Lay JC, Crump JA, et al: An outbreak of Salmonella Javiana associated with amphibian contact-Mississippi, 2001. Presented at the International Conference on Emerging Infectious Diseases Atlanta, Georgia; 2002.

287. Taylor R, Sloan D, Cooper T, Morton B, Hunter I: A waterborne outbreak of Salmonella Saintpaul. Commun Dis Intell 2000, 24(11):336-340.

288. Gaertner J, Wheeler PE, Obafemi S, Valdez J, Forstner MR, Bonner TH, Hahn D: Detection of salmonellae from fish in a natural river system. J Aquat Anim Health 2008, 20(3):150-157.

289. Onyango DM, Wandili S, Kakai R, Waindi EN: Isolation of Salmonella and Shigella from fish harvested from the Winam Gulf of Lake Victoria, Kenya. J Infect Dev Ctries 2009, 3(2):99-104.

290. Broughton El, Walker DG: Prevalence of antibiotic-resistant Salmonella in fish in Guangdong, China. Foodborne Pathog Dis 2009, 6(4):519-521.

291. Mohamed Hatha AA, Lakshmanaperumalsamy P: Prevalence of Salmonella in fish and crustaceans from markets in Coimbatore, South India. Food Microbiology 1997, 14(2):111-116.

292. Kodama H, Nakanishi Y, Yamamoto F, Mikami T, Izawah H, Imagawa T, Hasimoto Y, Kudo N: Salmonella arizonae isolated from a pirarucu, Arapaima gigas Cuvier, with septicaemia. J Fish Dis 1987, 10(6):509-512.

293. Bocek AJ, Brady YJ, Rogers WA: Exposure of silver carp, Hypophthalmichthys molitrix, to Salmonella Typhimurium. Aquaculture 1992, 103(1):9-16.

294. Lunestad BT, Nesse L, Lassen J, Svihus B, Nesbakken T, Fossum K, Rosnes JT, Kruse H, Yazdankhah S: Salmonella in fish feed; occurrence and implications for fish and human health in Norway. Aquaculture 2007, 265(1-4):1-8.

295. Musto J, Kirk M, Lightfoot D, Combs BG, Mwanri L: Multi-drug resistant Salmonella Java infections acquired from tropical fish aquariums, Australia, 2003-04. Commun Dis Intell 2006, 30(2):222-227.

296. Kurstak E, Vega C, Sonea S: Action of two strains of Salmonella Typhimurium on a lepidopteron. Bull World Health Organ 1968, 39(3):477-482, (article in French)..

297. Labrousse A, Chauvet S, Couillault C, Kurz CL, Ewbank JJ: Caenorhabditis elegans is a model host for Salmonella Typhimurium. Curr Biol 2000 10(23):1543-1545.

298. Greenberg B, Klowden M: Enteric bacterial interactions in insects. Am J Clin Nutr 1972, 25(12):1459-1466.

299. Jang YH, Lee SJ, Lim JG, Lee HS, Kim TJ, Park JH, Chung BH, Choe NH: The rate of Salmonella spp. infection in zoo animals at Seoul Grand Park, Korea. J Vet Sci 2008, 9(2):177-181.

300. Bauwens L, Vercammen F, Bertrand S, Collard JM, De Ceuster S: Isolation of Salmonella from environmental samples collected in the reptile department of Antwerp Zoo using different selective methods. J Appl Microbiol 2006, 101(2):284-289.
301. McMillian M, Dunn JR, Keen JE, Brady KL, Jones TF: Risk behaviors for disease transmission among petting zoo attendees. JAVMA 2007, 231(7).

302. Budgell S, Ing J, Elliot R: Salmonella enterica Outbreak Associated with an Agricultural Exhibition. Environmental Health Review 2004, 21-24, (Spring):.

303. Bender JB, Shulman SA: Reports of zoonotic disease outbreaks associated with animal exhibits and availability of recommendations for preventing zoonotic disease transmission from animals to people in such settings. JAVMA 2004, 224:1105-1109.

304. Smith KE, Stenzel SA, Bender JB, Wagstrom E, Soderlund D, Leano FT, Taylor CM, Belle-Isle PA, Danila R: Outbreaks of enteric infections caused by multiple pathogens associated with calves at a farm day camp. Pediatr Infect Dis J 2004, 23(12):1098-1104.

305. Fey PD, Safranek TJ, Rupp ME, Dunne EF, Ribot E, Iwen PC, Bradford PA, Angulo FJ, Hinrichs SH: Ceftriaxone-resistant Salmonella infection acquired by a child from cattle. N Engl J Med 2000, 342(17):1242-1249.

306. Visser IJ: Cutaneous salmonellosis in veterinarians. Vet Rec 1991, 129(16):364

307. Holmberg SD, Wells JG, Cohen ML: Animal-to-man transmission of antimicrobial-resistant Salmonella: investigations of U.S. outbreaks, 19711983. Science 1984, 225(4664):833-835.

308. Williams E: Veterinary Surgeons As Vectors of Salmonella Dublin. Br Med J 1980, 280(6217):815-818.

309. Pantekoek JF, Rhodes CS, Saunders JR: Salmonella folliculitis in veterinarians infected during obstetrical manipulation of a cow. Can Vet J 1974, 15(4):123-125.

310. Fish NA, Finlayson MC, Carere RP: Salmonellosis: report of a human case following direct contact with infected cattle. Can Med Assoc J 1967, 96(16):1163-1165.

311. Finlayson M: An outbreak of Salmonella Typhimurium in Alberta. Can J Public Health 1949, 40(9):396.

312. Bender JB, Hedberg CW, Boxrud DJ, Besser JM, Wicklund JH, Smith KE, Osterholm MT: Use of molecular subtyping in surveillance for Salmonella enterica serotype Typhimurium. N Engl J Med 2001, 344(3):189-195.

313. Morse EV, Kersting KW, Smith LE Jr, Myhrom EP, Greenwood DE: Salmonellosis: possible transmission from horse to human to dog of infection. Am J Public Health 1978, 68(5):497-499.

314. Baker JR: An outbreak of salmonellosis involving veterinary hospital patients. Vet Rec 1969, 85(1):8-10.

315. Bruner DW: A Note on Salmonella Abortus-equi Infection in Man. J Bacteriol 1946, 52(1):147.

316. CDC (Centers for Disease Control and Prevention): Outbreaks of multidrugresistant Salmonella Typhimurium associated with veterinary facilitiesIdaho, Minnesota, and Washington, 1999. MMWR Morb Mortal Wkly Rep 2001, 50(33):701-704

317. Cherry B, Burns A, Johnson GS, Pfeiffer $H$, Dumas N, Barrett D, McDonough PL, Eidson M: Salmonella Typhimurium outbreak associated with veterinary clinic. Emerg Infect Dis 2004, 10(12):2249-2251.

318. Tauni MA, Osterlund A: Outbreak of Salmonella Typhimurium in cats and humans associated with infection in wild birds. J Small Anim Pract 2000, 41(8):339-341.

319. Reynolds PJ: A Report. Epidemiological Bulletin 1974, 18:35-37.

320. Carter HS, Weir IB: A dog as a probable source of human infection with Salmonella Paratyphi-B. J Pathol Bacteriol 1952, 64(1):230-232.

321. Kauffmann F, Henningsen ED: A New Type of Salmonella from Man and Dog. Acta Pathologica Microbiologica Scandinavica 1939, 16:99-102.

322. Wolff AH, Henderson ND, MC CG: Salmonella from dogs and the possible relationship to salmonellosis in man. Am J Public Health Nations Health 1948, 38(3):403-408.

323. Caspersen J: A Paratyphoid Outbreak with a Peculiar Origin (Dog). Fork Norsk Med Sds K 1937, 10:138-143.

324. Magnusson KE: A Dog as a Source of Paratyphoid Infection. Ztschr Hyg u Infektionskr 1938, 121:136-138.

325. Silbergeld EK, Graham J, Price LB: Industrial food animal production, antimicrobial resistance, and human health. Annu Rev Public Health 2008, 29:151-169.

326. CDC (Centers for Disease Control and Prevention): Human salmonellosis associated with animal-derived pet treats-United States and Canada, 2005. MMWR Morb Mortal Wkly Rep 2006, 55(25):702-705.

327. Pitout JD, Reisbig MD, Mulvey M, Chui L, Louie M, Crowe L, Church DL, Elsayed S, Gregson D, Ahmed R, Tilley P, Hanson ND: Association between handling of pet treats and infection with Salmonella enterica serotype 
Newport expressing the AmpC beta-lactamase, CMY-2. J Clin Microbiol 2003, 41(10):4578-4582.

328. Human health risk from exposure to natural dog treats. Can Commun Dis Rep 2000, 26(6):41-42.

329. Porcalla AR, Rodriguez WJ: Soft tissue and cartilage infection by Salmonella Oranienburg in a healthy girl. South Med J 2001, 94(4):435-437.

330. Fish NA, Fletch AL, Butler WE: Family outbreak of salmonellosis due to contact with guinea pigs. Can Med Assoc J 1968, 99:418-420.

331. Fuller CC, Jawahir SL, Leano FT, Bidol SA, Signs K, Davis C, Holmes Y, Morgan J, Teltow G, Jones B, Sexton RB, Davis GL, Braden CR, Patel NJ, Deasy MP, Smith KE: A multi-state Salmonella Typhimurium outbreak associated with frozen vacuum-packed rodents used to feed snakes. Zoonoses Public Health 2008, 55(8-10):481-487.

332. CDC (Centers for Disease Control and Prevention): Outbreak of multidrugresistant Salmonella Typhimurium associated with rodents purchased at retail pet stores-United States, December 2003-October 2004. MMWR Morb Mortal Wkly Rep 2005, 54(17):429-433.

333. OzFoodNet: Foodborne disease in Australia: incidence, notifications and outbreaks. Annual report of the OzFoodNet network, 2002. Commun Dis Intell 2003, 27(2):209-243.

334. Craig C, Styliadis S, Woodward D, Werker D: African pygmy hedgehogassociated Salmonella Tilene in Canada. Can Commun Dis Rep 1997, 23(17):129-131, discussion 131-122.

335. CDC (Centers for Disease Control and Prevention): African pygmy hedgehog-associated salmonellosis-Washington, 1994. MMWR Morb Mortal Wkly Rep 1995, 44(24):462-463.

doi:10.1186/1297-9716-42-34

Cite this article as: Hoelzer et al: Animal contact as a source of human non-typhoidal salmonellosis. Veterinary Research 2011 42:34.

\section{Submit your next manuscript to BioMed Central and take full advantage of:}

- Convenient online submission

- Thorough peer review

- No space constraints or color figure charges

- Immediate publication on acceptance

- Inclusion in PubMed, CAS, Scopus and Google Scholar

- Research which is freely available for redistribution

Submit your manuscript at www.biomedcentral.com/submit
Biomed Central 